Article

\title{
On the Nature of Luminescence Thermochromism of Multinuclear Copper(I) Benzoate Complexes in the Crystalline State
}

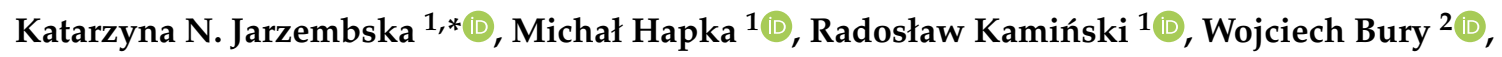 \\ Sylwia E. Kutniewska ${ }^{1}$, Dariusz Szarejko ${ }^{1}{ }^{(1)}$ and Małgorzata M. Szczęśniak ${ }^{3}$ (i) \\ 1 Department of Chemistry, University of Warsaw, Żwirki i Wigury 101, 02-089 Warsaw, Poland; \\ michal.hapka@gmail.com (M.H.); rkaminski85@uw.edu.pl (R.K.); sekutyla@gmail.com (S.E.K.); \\ szarejkodariusz@gmail.com (D.S.) \\ 2 Department of Chemistry, University of Wrocław, Joliot-Curie 14, 50-383 Wrocław, Poland; \\ wojciech.bury@gmail.com \\ 3 Department of Chemistry, Oakland University, 146 Library Drive, Rochester, MI 48309-4479, USA; \\ bryant@oakland.edu \\ * Correspondence: katarzyna.jarzembska@gmail.com
}

Received: 30 November 2018; Accepted: 6 January 2019; Published: 12 January 2019

\begin{abstract}
A model luminescent $\left[\left(\mathrm{PhCO}_{2}\right)_{4} \mathrm{Cu}_{4}\right]\left(\mathrm{Cu}_{4}\right)$ complex in the crystalline state was investigated via combined crystallographic and spectroscopic techniques contributed substantially by theoretical modelling. The complex appeared to exhibit luminescence thermochromism, i.e., red phosphorescence at room temperature which changes to green when lowering the temperature to $90 \mathrm{~K}$. The low-energy emissive state was assigned as a cluster-centred triplet, ${ }^{3} \mathrm{CC}$. The emission from this state predicted in TDDFT $(\sim 635 \mathrm{~nm})$ matches the experimental red band observed at 660-715 nm. In contrast, the nature of the high-energy "green" band was less straightforward. The next reached cluster-centred triplet excited state occurred to be energetically close to the experimental value of $\sim 545 \mathrm{~nm}$. The two excited states also exhibit significant metal-to-ligand and ligand-to-metal charge transfer characteristics, especially for solid-state distorted geometries. In both cases the cluster core was expected to become notably contracted when compared to the ground state. Time-resolved photocrystallographic results supported the computationally predicted core contraction upon excitation. Additionally, the differences between the spectroscopic behaviour of the related tetra- and hexanuclear copper(I) complexes, $\mathbf{C u}_{4}$ and $\mathbf{C u}_{6}$ (i.e., $\left.\left[\left(\mathrm{PhCO}_{2}\right)_{6} \mathrm{Cu}_{6}\right]\right)$ in the crystalline state were discussed and examined. It appeared that crystal packing may constitute an important factor as far as the lack of luminescence thermochromism in the latter case is concerned. Synopsis: Structure-property relationships characterising a model luminescent $\left[\left(\mathrm{PhCO}_{2}\right)_{4} \mathrm{Cu}_{4}\right]\left(\mathrm{Cu}_{4}\right)$ complex in the crystalline state were investigated via combined crystallographic and spectroscopic techniques contributed by theoretical modelling, and compared with the properties of the related $\left[\left(\mathrm{PhCO}_{2}\right)_{6} \mathrm{Cu}_{6}\right]\left(\mathrm{Cu}_{6}\right)$ complex.
\end{abstract}

Keywords: cuprophilic interactions; luminescence thermochromism; photocrystalographic studies; solid-state spectroscopy; theoretical calculations; electronic excited states

\section{Introduction}

One of the most important current areas in chemistry is developing new functional and controllable materials for technological applications. Therefore, compounds exhibiting specific photoactive properties, either in solution or, even more importantly, in the solid state, are among the most desired materials nowadays. A number of such systems have already found versatile applications 
in solar-energy conversion [1] and other fields, ranging from molecular electronics [2], light-emitting diodes (LEDs) [3], through photocatalysts [4], to biolabels [5].

Among many photoactive substances, transition-metal complexes seem to be the most interesting ones due to several reasons, two of which are: (i) the presence of metal centres induces spectroscopic properties related to metal-ligand interactions not achievable for purely organic molecules, and (ii) the flexibility in designing new molecules by changing metal centres and organic ligands, which allows fine-tuning of desired properties. In this respect, $\mathrm{Cu}^{\mathrm{I}}$ compounds are distinctive, as they provide an attractive alternative to expensive, less abundant, and more toxic heavy-metal-containing complexes [6]. Furthermore, polynuclear $\mathrm{d}^{10}$ copper complexes may create diverse molecular assemblies and are often unusually strongly luminescent. Their photochemical properties can be modified by the choice of ligands and by variation of a number of metal centres. Since the $\mathrm{d}^{10}$ electronic configuration of $\mathrm{Cu}^{\mathrm{I}}$ enforces no stereochemical demands, the coordination sphere, normally four-coordinate, is therefore largely determined by electrostatic and molecular mechanical factors [7]. An advantage of $\mathrm{Cu}^{\mathrm{I}}$ systems over many first-row transition metal complexes is also the fact that the luminescence of the latter ones is often bypassed by the presence of low-lying ligand-field excited states (ESs), which may be too short-lived to have measurable emissions [8]. In this context, filled-shell $\mathrm{d}^{10}$ systems offer an opportunity to observe other excited states. For instance, tetranuclear cuprous halide clusters usually display thermochromic properties thanks to two distinct emission bands of different emission lifetimes $[9,10]$. In the literature-reported $\left[\mathrm{Cu}_{4} \mathrm{I}_{4}(\mathrm{py})_{4}\right]$ case (py $=$ pyridine), for example, the strong lower energy emission was assigned to a triplet cluster-centred $\left({ }^{3} \mathrm{CC}\right) \mathrm{ES}$, a combination of iodide-to-copper charge transfer (XMCT) and $\mathrm{d} \rightarrow \mathrm{s}$ transitions, and the weaker higher-energy band to a triplet halide-to-ligand charge transfer $\left({ }^{3} \mathrm{XLCT}\right) \mathrm{ES}$. This subject was well-described in the review by Ford et al. [7].

In the current paper, we will focus our attention on the tetranuclear $\left[\left(\mathrm{PhCO}_{2}\right)_{4} \mathrm{Cu}_{4}\right]$ complex $\left(\mathbf{C u}_{4}\right.$, Scheme 1a). This compound has already been studied regarding its structure, interesting reversible interconversion, via sublimation and subsequent recrystallization, into the $\left[\left(\mathrm{PhCO}_{2}\right)_{6} \mathrm{Cu}_{6}\right]$ form $\left(\mathbf{C u}_{6}\right.$, Scheme $\left.1 \mathrm{~b}\right)$, and some selected aspects of its spectroscopic properties [11]. Nonetheless, our preliminary examination of $\mathbf{C u}_{4}$ revealed that the complex additionally exhibits thermochromic emission in its crystal form, which has not been detected in the previous studies. This suggests that, similarly to the mentioned $\left[\mathrm{Cu}_{4} \mathrm{I}_{4}(\mathrm{py})_{4}\right]$ cluster, there exist at least two distinct emissive excited states. These, however, are definitely of different origin than those described for the iodide complex. Interestingly, such properties are not exhibited by the related hexanuclear $\mathbf{C u}_{6}$ form, for which, in turn, temperature-induced structural phase transition was observed.

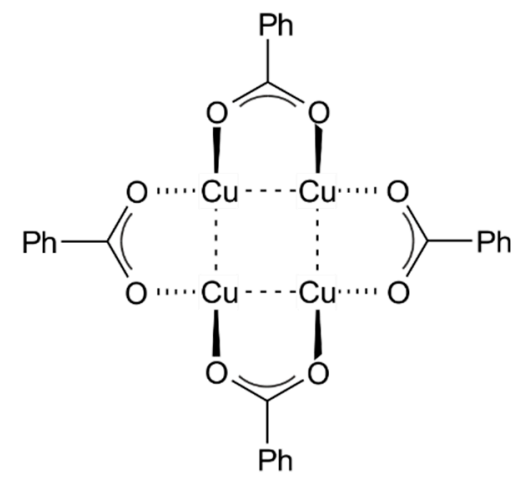

(a)

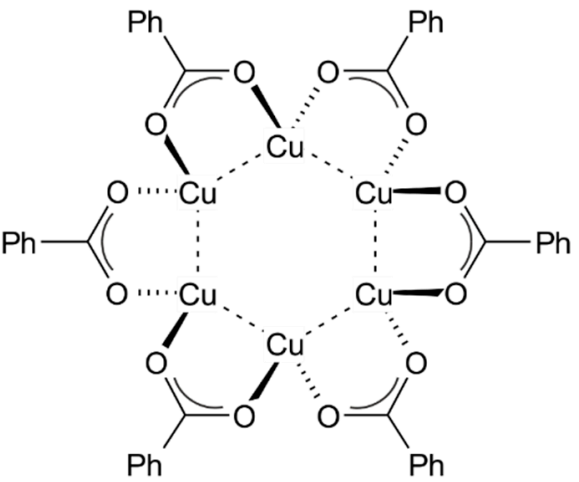

(b)

Scheme 1. Schematic representation of $\mathbf{C u}_{4}(\mathbf{a})$ and $\mathbf{C u}_{6}(\mathbf{b})$ complexes $(\mathrm{Ph}=$ phenyl).

Hence, this paper is devoted to a thorough study of the nature of the luminescence thermochromism found by us for the $\mathrm{Cu}_{4}$ crystal form, using time-resolved spectroscopic and photocrystallographic 
methods at different temperatures, largely contributed by theoretical computations. Furthermore, an attempt of understanding the striking difference between the spectroscopic behaviour of the related $\mathbf{C u}_{4}$ and $\mathbf{C u}_{6}$ complexes in the solid state has been undertaken.

\section{Experimental Section}

\subsection{Synthesis and Crystallisation}

The $\mathbf{C} \mathbf{u}_{4}$ complex was synthesised according to the literature procedure [11]. This procedure yielded a phase pure crystalline powder of the $\mathbf{C} \mathbf{u}_{4}$ complex. Single rod-shaped crystals of $\mathbf{C u}_{4}$ were obtained by slow crystallization of the complex from saturated xylene solution. Additionally, crystals of the $\mathbf{C} \mathbf{u}_{6}$ complex were obtained, as described in the literature, namely by the sublimation of the $\mathbf{C} \mathbf{u}_{4}$ powder [11].

\subsection{X-ray Diffraction Data Collection and Refinement}

All single-crystal X-ray measurements of both compounds were carried out on a classical diffractometer, in all cases equipped with the CCD detector and low-temperature open-flow device to keep the samples at the constant temperature. Data collection strategies determination and optimization, unit cell determination, raw diffraction image integration, and data scaling, were all performed using the appropriate algorithms implemented in the diffractometer software [12,13].

All structures were solved using a charge-flipping method [14-16], as implemented in the SUPERFLIP program [17], and refined with the JANA package [18] within the independent atom model (IAM) approximation. CIF files for each refinement are present in the Supplementary Materials, or can be retrieved from the Cambridge Structural Database [19] (for deposition numbers see Table S1 in the Supplementary Materials). All raw data and associated refinement files are available under the following DOI: 10.18150/repod.0196712 (Repository for Open Data, Interdisciplinary Centre for Mathematical and Computational Modelling, University of Warsaw, Warsaw, Poland).

\subsection{Solid-State Spectroscopy}

Single-crystal emission spectra and luminescence lifetimes were measured on an in-house -build setup at the Department of Chemistry of the University at Buffalo, NY, USA [20], and on a similar setup recently installed by us at the Department of Chemistry of the University of Warsaw. In the latter case samples were UV-light-excited with the Opotek Vibrant Nd:YAG laser $(\lambda=355 \mathrm{~nm}$, pulse length of about $5 \mathrm{~ns}$ ). The laser output was delivered to the rear port of an Olympus IX73 (Warsaw, Poland) inverted microscope and focused on the sample using a reflective objective. Any residual or scattered UV-light was cut off from reaching the eyepieces or detector with an appropriate dichroic mirror. The single-crystal samples, placed at the quartz plate with the aid of the Type-F Olympus immersion oil, were mounted inside the microscope cryostage (Cryo Industries of America, Manchester, NH, USA) which allows one to cool the crystal down to $90 \mathrm{~K}$. Emission from the sample was recollected through the reflective objective and delivered to the spectrograph (Acton SP2150; Princeton Instruments; Trenton, NJ, USA) equipped with the time-gated intensified charge-coupled device (ICCD) camera (PI-MAX4, Princeton Instruments). In this setup the laser flash-lamp was used to trigger the CCD camera, which in turn, after a specified time delay triggered the laser Q-switch allowing for a precise control of the detector readout delay throughout the experiment. The experiment was controlled using the LightField software (Princeton Instruments) allowing variations of the time delay and, thus, enabling collecting of the sample emission as a function of time. The luminescence lifetimes were extracted from the intensity decay data by means of the least-squares fitting (Supplementary Materials). 


\subsection{Theoretical Computations}

All non-metal atoms were described using the cc-pVDZ Dunning basis set [21]. For the $\mathrm{Cu}$ atoms the cc-pVDZ-PP basis set of Peterson \& Puzzarini [22] combined with the relativistic effective core potential of Figgen et al. [23], was employed. The CAM-B3LYP [24] and $\omega$ B97XD [25] range-separated exchange-correlation density functional approximations were used, the former supplemented with the pairwise D3 dispersion correction [26].

The quantum-mechanics/molecular mechanics (QM/MM) calculations were performed using the ONIOM approach [27], so as to emulate the crystalline environment [28]. Molecular clusters were prepared with the CLUSTERGEN program [29], based on the experimental data, in which the C-H distances were fixed at the neutron-normalised values. The high-layer encompassed a single $\mathrm{Cu}_{4}$ molecule, and was calculated at the $\omega \mathrm{B} 97 \mathrm{XD}$ level. In turn, the electronic embedding was constructed employing Hirshfeld charges obtained at the CAM-B3LYP/cc-pVDZ level of theory. All calculations were conducted using the GAUSSIAN package (GAUSSIAN16 edition) [30]. The analysis of one-particle transition density matrices (1-TDMs) [31,32] was carried out using the THEODORE program package (version 1.2) [33].

\subsection{Time-Resolved Laue Studies}

The time-resolved laser-pump/X-ray-probe data sets were collected at the 14-ID beamline in the BioCARS station at the Advanced Photon Source (APS; Chicago, Illinois, USA) [34] at a $15 \mathrm{keV}$ undulator setting (polychromatic radiation, $\lambda \approx 0.8-1.0 \AA$; single X-ray pulse length of about $80 \mathrm{ps}$ ). Crystals were mounted on glass fibres using Paratone $N$ oil or epoxy glue, for $90 \mathrm{~K}$ and $225 \mathrm{~K}$ data set collections, respectively. Optimal laser power was selected on the basis of preliminary short scans and the so-called correlation plot analysis [35]. The $90 \mathrm{~K}$ data sets were collected using the $\mathrm{Nd}$ :YAG/OPO nanosecond laser setup with a $355 \mathrm{~nm}$ excitation wavelength, in turn, the $225 \mathrm{~K}$ data sets were collected using a Ti:sapphire laser tuned to $360 \mathrm{~nm}$. The applied laser power varied within $0.7-1.8 \mathrm{~mJ} \cdot \mathrm{mm}^{-2}$ per pulse for different measurements. Light-ON and light-OFF frames were recorded in the prompt succession to minimise the effect of long-range fluctuations in the beam's position and/or intensity [36,37]. Raw data sets are available under the following DOI: 10.18150/repod.0196712. More details are available from the Supplementary Materials.

Data processing pipeline is based on the so-called RATIO method [38,39]. In this approach the final result of the data reduction are the light-ON and light-OFF reflection intensity ratios $\left(R_{\mathrm{o}}=\right.$ $I_{\mathrm{O}}^{\mathrm{ON}} / I_{\mathrm{O}}^{\mathrm{OFF}}=\left|F_{\mathrm{O}}^{\mathrm{ON}}\right|^{2} /\left|F_{\mathrm{O}}^{\mathrm{OFF}}\right|^{2}$ ), which are then used to estimate "monochromatic" structure factor amplitudes not spurred by the wavelength dependence present in the original Laue diffraction data. The diffraction spot intensities from the Laue experiment were integrated with our new locally-written software [40], and later indexed by the modified version of the LAUEUTIL software package [41,42]. The resulting intensity ratios were averaged with the SORTAV program $[43,44]$. Finally, photodifference maps [45] were plotted based on the merged and scaled [46,47] data according to the following general equation:

$$
\Delta \varrho_{\text {pdiff }}(\mathbf{r})=\frac{1}{V} \sum_{k}\left(\sqrt{R_{\mathrm{o}, k}} \cdot\left|F_{\mathrm{o}, k}^{\mathrm{mOFF}}\right|-\left|F_{\mathrm{o}, k}^{\mathrm{mOFF}}\right|\right) e^{\mathrm{i} \phi_{\mathrm{c}, k}^{\mathrm{mOFF}}} e^{2 \pi \mathbf{i}_{k} \cdot \mathbf{r}}
$$

where $R_{\mathrm{o}, k}$ are synchrotron-derived intensity ratio values, $F_{\mathrm{o}}^{\mathrm{mOFF}}$ are the reference observed structure factors from the monochromatic light-OFF measurement, while $\phi_{\mathrm{c}}^{\mathrm{mOFF}}$ constitute the calculated structure factor phases from the same monochromatic data. More details are available from the Supplementary Materials. 


\section{Results and Discussion}

\subsection{Crystal Structures of the $\mathrm{Cu}_{4}$ and $\mathrm{Cu}$ Complexes}

The studied tetranuclear $\mathrm{Cu}_{4}$ complex (i.e., $\left.\left[\left(\mathrm{PhCO}_{2}\right)_{4} \mathrm{Cu}_{4}\right]\right)$ crystallises in the triclinic $P \overline{1}$ space group with two molecules in the asymmetric unit (Figure 1). These molecules differ somewhat in the geometry of the metal core (Table 1), but they share the general structural features. The metal core of the molecule $\mathrm{A}$ is characterised by, on the average, slightly longer $\mathrm{Cu}-\mathrm{Cu}$ bonds, however, the shorter diagonal of the formed rhomboid can still be classified as a metal-metal bond at $90 \mathrm{~K}$ (based on the van der Waals radii criteria), which is not the case as far as the second symmetry-independent molecule B is concerned. The metal core of the molecule $\mathrm{A}$ is also more regular and resembles a parallelogram with two longer (ca. $2.73 \AA$ at $90 \mathrm{~K}$ ) and two shorter edges (ca. $2.71 \AA$ at $90 \mathrm{~K}$ ). For the purpose of this study, the $\mathbf{C u}_{4}$ crystal structure was determined also at $225 \mathrm{~K}, 250 \mathrm{~K}$, and RT in order to catch any structural changes which could be related to the temperature spectroscopic behaviour of the system. It appeared that, the analysed crystal structure does not undergo any phase transition in the temperature range between $90 \mathrm{~K}$ and room temperature (RT). In general, temperature influences the lattice and geometrical parameters in a typical way. Regarding the core shapes, the copper-copper distances get elongated except for the longer diagonal in the B molecule, which shortens with temperature rise. Furthermore, both metal cores become slightly more 'square-like', i.e., the obtuse angles diminish, whereas the acute ones increase (the average changes though do not exceed about $2^{\circ}$ ).

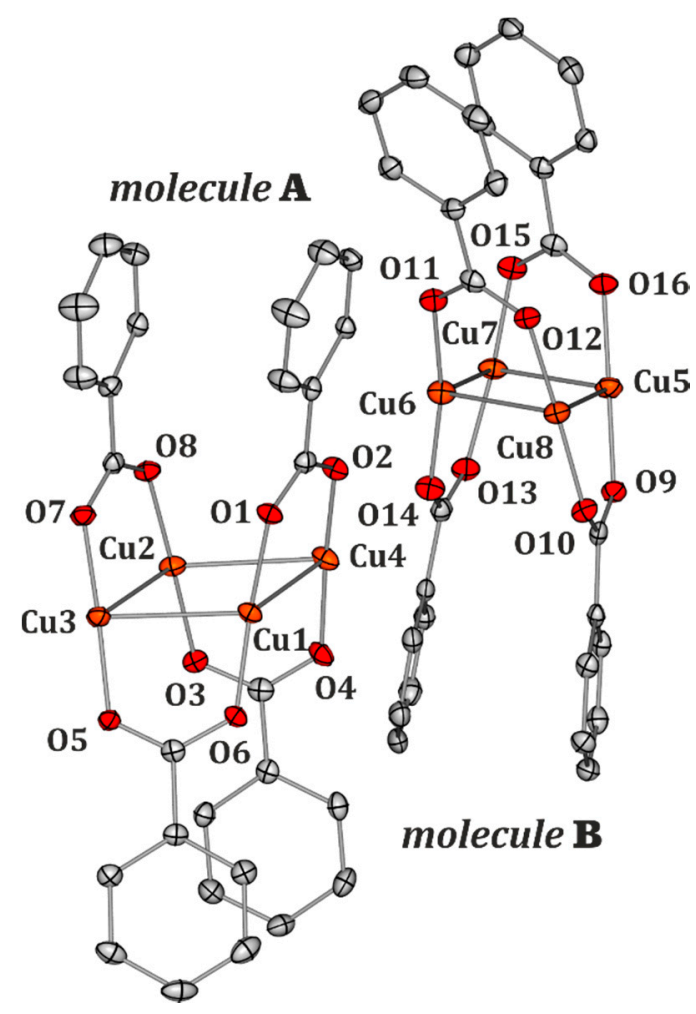

Figure 1. Molecular structures of two symmetry-independent molecules of $\mathbf{C} \mathbf{u}_{4}$ in the crystal lattice ( $90 \mathrm{~K}$ data set used). Atomic thermal motion is represented as ellipsoids ( $50 \%$ probability level). Hydrogen atoms have been removed for clarity. 
Table 1. Selected geometrical parameters describing the molecular cores of both independent molecules present in the $\mathbf{C u}_{4}$ crystal structure at different temperatures.

\begin{tabular}{|c|c|c|c|c|c|}
\hline \multirow{2}{*}{ Molecule } & \multirow{2}{*}{ Bond Distance, $d / \AA ̊$} & \multicolumn{4}{|c|}{ Temperature, $T / \mathrm{K}$} \\
\hline & & 90 & 225 & 250 & RT II $^{\text {II }}$ \\
\hline \multirow[t]{6}{*}{$\mathrm{A}$} & $\mathrm{Cu} 1-\mathrm{Cu} 3$ & $2.7061(9)$ & $2.7140(5)$ & $2.7141(6)$ & $2.719(2)$ \\
\hline & $\mathrm{Cu} 1-\mathrm{Cu} 4$ & $2.7335(7)$ & $2.7564(7)$ & $2.7547(6)$ & $2.7625(9)$ \\
\hline & $\mathrm{Cu} 2-\mathrm{Cu} 3$ & $2.7129(7)$ & $2.7324(7)$ & $2.7323(6)$ & $2.7391(9)$ \\
\hline & $\mathrm{Cu} 2-\mathrm{Cu} 4$ & $2.7325(9)$ & $2.7573(5)$ & $2.7592(6)$ & $2.769(2)$ \\
\hline & $\mathrm{Cu} 1 \cdots \mathrm{Cu} 2^{¥}$ & $2.8726(8)$ & $2.9251(7)$ & $2.9351(6)$ & $2.958(1)$ \\
\hline & $\mathrm{Cu} 3 \cdots \mathrm{Cu} 4 \ddagger$ & $4.622(1)$ & $4.6335(6)$ & $4.6272(7)$ & $4.630(2)$ \\
\hline \multirow[t]{6}{*}{ B } & $\mathrm{Cu} 5-\mathrm{Cu} 7$ & $2.7256(9)$ & $2.7401(6)$ & $2.7426(7)$ & $2.751(2)$ \\
\hline & $\mathrm{Cu} 5-\mathrm{Cu} 8$ & $2.7025(7)$ & $2.7199(8)$ & $2.7182(7)$ & $2.7264(9)$ \\
\hline & $\mathrm{Cu} 6-\mathrm{Cu} 7$ & $2.7118(7)$ & $2.7266(8)$ & $2.7239(7)$ & $2.7315(9)$ \\
\hline & $\mathrm{Cu} 6-\mathrm{Cu} 8$ & $2.7113(9)$ & $2.7215(6)$ & $2.7240(7)$ & $2.727(2)$ \\
\hline & $\mathrm{Cu} 5 \cdots \mathrm{Cu} 6^{¥}$ & $3.0797(9)$ & $3.1450(6)$ & $3.1527(7)$ & $3.185(2)$ \\
\hline & $\mathrm{Cu} 7 \cdots \mathrm{Cu} 8 \ddagger$ & $4.4668(8)$ & $4.4560(8)$ & $4.4509(7)$ & $4.444(1)$ \\
\hline \multirow{2}{*}{ Molecule } & \multirow{2}{*}{ Valence Angle, $\theta /^{\circ}$} & \multicolumn{4}{|c|}{ Temperature, $T / \mathrm{K}$} \\
\hline & & 90 & 225 & 250 & RT II $^{\text {II }}$ \\
\hline \multirow[t]{4}{*}{$\mathrm{A}$} & $\mathrm{Cu} 3-\mathrm{Cu} 1-\mathrm{Cu} 4$ & $116.37(2)$ & $115.77(2)$ & $115.58(2)$ & $115.27(2)$ \\
\hline & $\mathrm{Cu} 3-\mathrm{Cu} 2-\mathrm{Cu} 4$ & $116.17(2)$ & $115.13(2)$ & $114.83(2)$ & $114.40(2)$ \\
\hline & $\mathrm{Cu} 1-\mathrm{Cu} 3-\mathrm{Cu} 2$ & $64.03(2)$ & $64.97(2)$ & $65.22(1)$ & $65.63(2)$ \\
\hline & $\mathrm{Cu} 1-\mathrm{Cu} 4-\mathrm{Cu} 2$ & $63.41(2)$ & $64.08(2)$ & 64.32(1) & $64.65(2)$ \\
\hline \multirow[t]{4}{*}{ B } & $\mathrm{Cu} 7-\mathrm{Cu} 5-\mathrm{Cu} 8$ & $110.75(2)$ & $109.39(2)$ & $109.19(2)$ & $108.47(2)$ \\
\hline & $\mathrm{Cu} 7-\mathrm{Cu} 6-\mathrm{Cu} 8$ & $110.91(2)$ & $109.75(2)$ & $109.57(2)$ & $109.01(2)$ \\
\hline & $\mathrm{Cu} 5-\mathrm{Cu} 7-\mathrm{Cu} 6$ & $69.00(2)$ & $70.24(2)$ & $70.44(2)$ & $71.04(2)$ \\
\hline & $\mathrm{Cu} 5-\mathrm{Cu} 8-\mathrm{Cu} 6$ & $69.34(2)$ & $70.62(2)$ & $70.80(2)$ & $71.47(2)$ \\
\hline
\end{tabular}

II Room temperature. ${ }^{¥}$ Short diagonal. ${ }^{\ddagger}$ Long diagonal.

As already mentioned, the crystal structure of the $\mathbf{C u}_{6}$ complex (Figure 2) behaves unlike that of $\mathbf{C u}_{4}$ with changes of temperature. Although it also forms the triclinic $P \overline{1}$ crystal lattice, it is differently packed depending on temperature (Figure 2). Below $253 \mathrm{~K}$ the asymmetric unit contains a half of the $\mathbf{C u}_{6}$ molecule, which is located at the centre of symmetry. Between $253 \mathrm{~K}$ and $263 \mathrm{~K} \mathrm{a}$ phase transition is observed, as described in the literature [11], leading to two independent halves of the $\mathbf{C u}_{6}$ complex comprising the asymmetric unit at higher temperatures (Figure 2). The crystal packing similarities and differences between the $293 \mathrm{~K}$ and at $173 \mathrm{~K}$ crystal structures of $\mathbf{C u}_{6}$ have already been discussed by Filatov et al. [11]. Our X-ray diffraction measurement conducted at $90 \mathrm{~K}$ confirms that there are no other phase transitions down to this temperature point. Geometrical parameters characterising the $\mathbf{C u}_{6}$ copper cores at $90 \mathrm{~K}$ and at $\mathrm{RT}$ are collected in Table 2. Again, the copper-copper distances tend to elongate with increasing temperature. The $\mathbf{C u}_{6}$ molecules do not exhibit the inter-core $\mathrm{Cu}$. . Cu short diagonal contacts, as indicated by the respective distances. The $\mathrm{Cu}-\mathrm{Cu}$ bonds in $\mathrm{Cu}_{6}$, however, are on average shorter than in the case of $\mathbf{C u}_{4}$. Additionally, in the case of the high-temperature phase, the symmetry-independent molecules are very much alike, in contrast to two molecules comprising ASU in the $\mathbf{C} \mathbf{u}_{4}$ crystal structure. Furthermore, the geometries of all the $\mathbf{C u}_{6}$ species at both high- and low-temperature crystal forms resemble each other more than the $\mathrm{Cu}_{4}$ symmetry-independent molecules. 


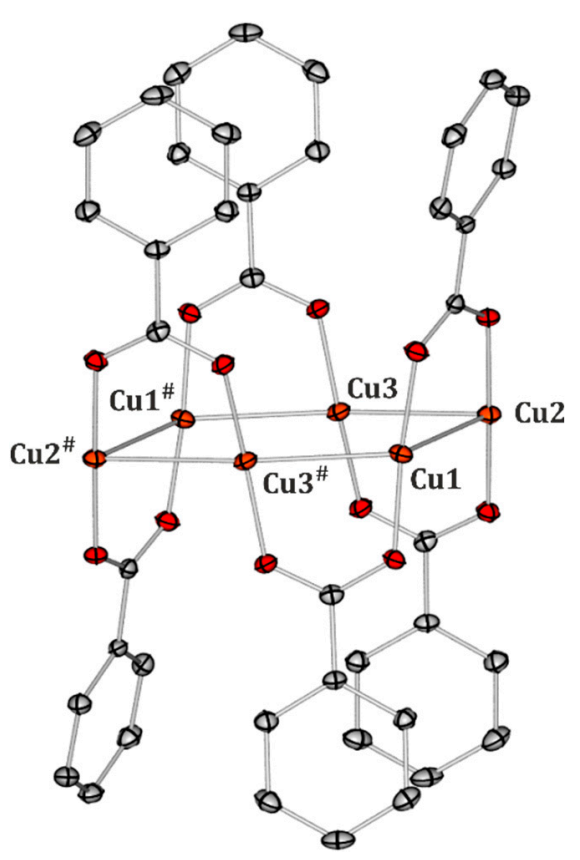

(a)

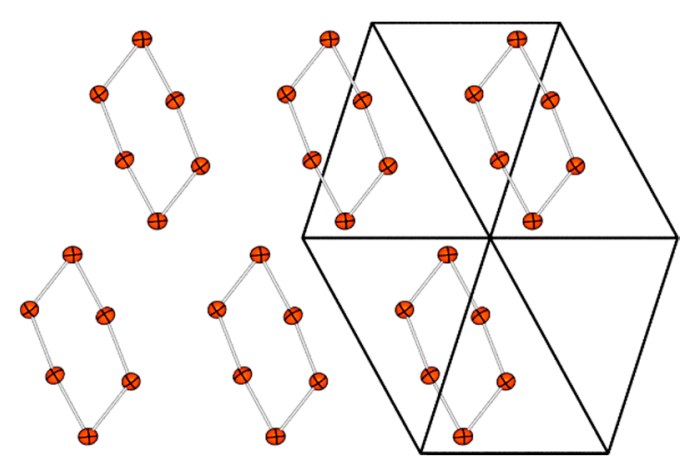

(b)

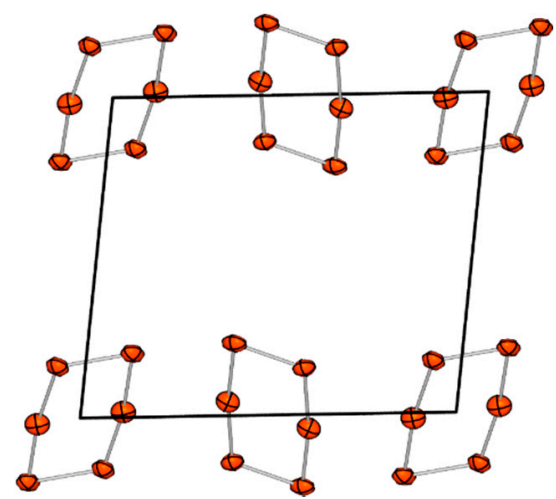

(c)

Figure 2. (a) Molecular structure of the $\mathbf{C} \mathbf{u}_{6}$ complex at $90 \mathrm{~K}$ (atomic thermal motion is represented as ellipsoids drawn at a $50 \%$ probability level; hydrogen atoms have been removed for clarity; (\#) symmetry operation: $-x+1,-y+1,-z+1)$. (b,c) Packing of the $\mathbf{C} \mathbf{u}_{6}$ molecules at $90 \mathrm{~K}(\mathbf{b})$ and $290 \mathrm{~K}$ (c) (only copper cores are shown; ellipsoids drawn at $90 \%$ and 50\%, respectively; panel (b) —view along [111] direction, panel (c)—view along [001] direction).

Table 2. Selected bond distances describing the metal cores' geometries in the $\mathbf{C} \mathbf{u}_{\mathbf{6}}$ crystal structures at different temperatures.

\begin{tabular}{cccc}
\hline \multirow{2}{*}{ Bond Distance, $d / \mathbf{\AA}$} & \multicolumn{3}{c}{ Temperature, T/K } \\
\cline { 2 - 4 } & $\mathbf{9 0}$ & $\mathbf{2 9 0} \mathbf{I I}^{\mathrm{I}}$ & $\mathbf{2 9 0}{ }^{\mathbf{}}$ \\
\hline $\mathrm{Cu} 1-\mathrm{Cu} 2$ & $2.6817(5)$ & $2.700(1)$ & $2.693(1)^{\S}$ \\
$\mathrm{Cu} 1-\mathrm{Cu} 3 \ddagger$ & $2.7131(4)$ & $2.747(1)$ & $2.760(1)^{\S}$ \\
$\mathrm{Cu} 2-\mathrm{Cu} 3$ & $2.6687(4)$ & $2.689(1)$ & $2.697(1)^{\S}$ \\
\hline
\end{tabular}

1st molecule in ASU (contains Cu1, Cu2, and Cu3 atoms). ${ }^{¥}$ 2nd molecule in ASU (contains Cu4, Cu5, and Cu6 atoms).

$\S$ Values given for respective bonds of 2 nd molecule as in the 1st molecule in ASU. $¥$ Symmetry transformations: $-x$

$+1,-y+2,-z+1$ (for molecule at $90 \mathrm{~K}),-x,-y+2,-z+1$ (for 1st molecule at $290 \mathrm{~K}),-x+2,-y+1,-z$ (for 2 nd molecule at $290 \mathrm{~K})$.

\subsection{Single-Crystal Luminescence Characterisation}

In order to quantitatively relate spectroscopic features with the X-ray-derived crystal structures, multi-temperature time-resolved single-crystal spectroscopic experiments were performed for the studied systems. Such proceedings also eliminated problems encountered for powder samples which may contain amorphous phase impurities that affect their properties (e.g., excited states' lifetimes). Our experiments revealed that crystals of the $\mathbf{C} \mathbf{u}_{4}$ complex exhibit two emission bands in the visible-light spectral region, namely the red band, $\sim 680 \mathrm{~nm}$, and the green band, $546 \mathrm{~nm}$ (Figure 3, Table 3). At high-temperature, the emission is clearly orange ( $250 \mathrm{~K})$ to red (RT), but at lower temperatures it becomes yellow, yellow-green to intensively green at $90 \mathrm{~K}$ (Figure S1, Supplementary 
Materials [48]). Indeed, when taking a closer look at the emission spectra at different temperatures, at RT almost exclusively the low-energy red band is visible, whereas the very weak green-band signal can be spotted only in the short time scale. In turn, while the temperature is being decreased, the high-energy green band gradually becomes stronger. At $200 \mathrm{~K}$, the green band is still much less intensive than the other one, however, below $150 \mathrm{~K}$ it is clearly dominant. At $90 \mathrm{~K}$, the high-energy band is very strong, while the low-energy band is almost fully suppressed, which is reflected in a brightly green emission of the sample (Supplementary Materials). The numerical parameters describing the emission maxima and the estimated emission decay lifetimes at different temperatures are presented in Table 3.

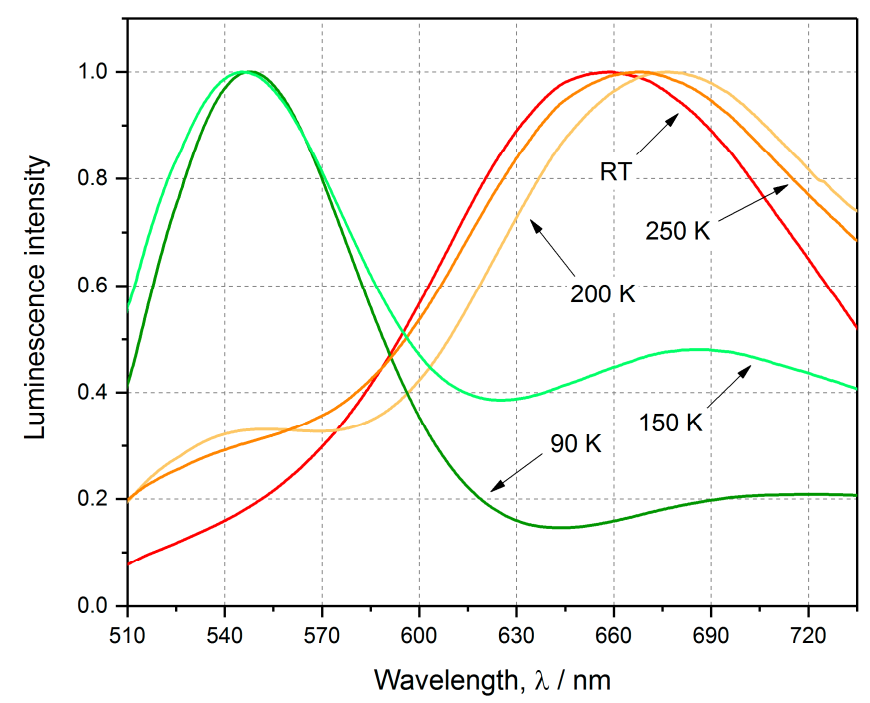

Figure 3. Emission spectra (smoothed and normalised) recorded for the $\mathbf{C} \mathbf{u}_{\mathbf{4}}$ crystal at different temperatures (excitation wavelength, $\lambda_{\mathrm{ex}}=355 \mathrm{~nm}$ ).

Table 3. The $\mathbf{C u}_{4}$ complex solid-state luminescence lifetimes $(\tau)$ and emission peak maxima $\left(\lambda_{\mathrm{em}}\right)$ obtained from the least-squares fit at various temperatures $(T) . \tau_{1}$ and $\tau_{\mathrm{s}}$ denote longer and shorter lifetime, respectively; " $\mathrm{r}$ " and " $\mathrm{g}$ " superscripts denote parameters for red- and green-light emission maxima, respectively.

\begin{tabular}{ccccccc}
\hline $\mathbf{T} / \mathbf{K}$ & $\boldsymbol{\tau}_{\mathbf{s}}^{\mathbf{r}} / \mu \mathbf{s}$ & $\tau_{\mathbf{1}}^{\mathbf{r}} / \boldsymbol{\mu s}$ & $\lambda_{\mathbf{e m}}^{\mathbf{r}} / \mathbf{n m}$ & $\tau_{\mathbf{s}}^{\mathrm{g}} / \mu \mathbf{s}$ & $\tau_{\mathbf{1}}^{\mathbf{g}} / \mu \mathbf{s}$ & $\lambda_{\mathbf{e m}}^{\mathrm{g}} / \mathbf{n m}$ \\
\hline 90 & $11.6(3)$ & $66.4(5)$ & 718 & $15.3(4)$ & $111.0(6)$ & 547 \\
150 & $5.2(1)$ & $61.3(3)$ & 682 & $10.4(2)$ & $61.0(4)$ & 546 \\
200 & $2.5(3)$ & $35.5(2)$ & 673 & $5.4(1)$ & $27.6(6)$ & 546 \\
250 & $2.13(4)$ & $10.16(4)$ & 668 & $-{ }^{b}$ & $-{ }^{b}$ & $-{ }^{b}$ \\
$\mathrm{RT}^{a}$ & $0.47(2)$ & $1.65(2)$ & 660 & $-{ }^{b}$ & $-{ }^{b}$ & $-{ }^{b}$ \\
\hline
\end{tabular}

${ }^{a}$ RT-room temperature. ${ }^{b}$ Impossible to determine with current experimental setup (emission decay is very fast).

It appears that the emission decay can be efficiently modelled by a bi-exponential function in the case of both band types. The temperature influences strongly the emission decay lifetimes, which are significantly shorter at high temperatures. The green band maximum does not shift with temperature, while the red band maximum shifts notably from about $715 \mathrm{~nm}$ at $90 \mathrm{~K}$ to $660 \mathrm{~K}$ determined at RT.

Interestingly, in the case of the related $\mathbf{C u}_{6}$ compound, crystals of which undergo the phase transition between 253 and $263 \mathrm{~K}$, the emission maximum shifts only from $586 \mathrm{~nm}$ at $90 \mathrm{~K}$ to $577 \mathrm{~nm}$ at RT (Figure 4). Furthermore, the temperature has also weaker effect on the emission decay lifetime when compared to $\mathrm{Cu}_{4}$ (Table 4). 


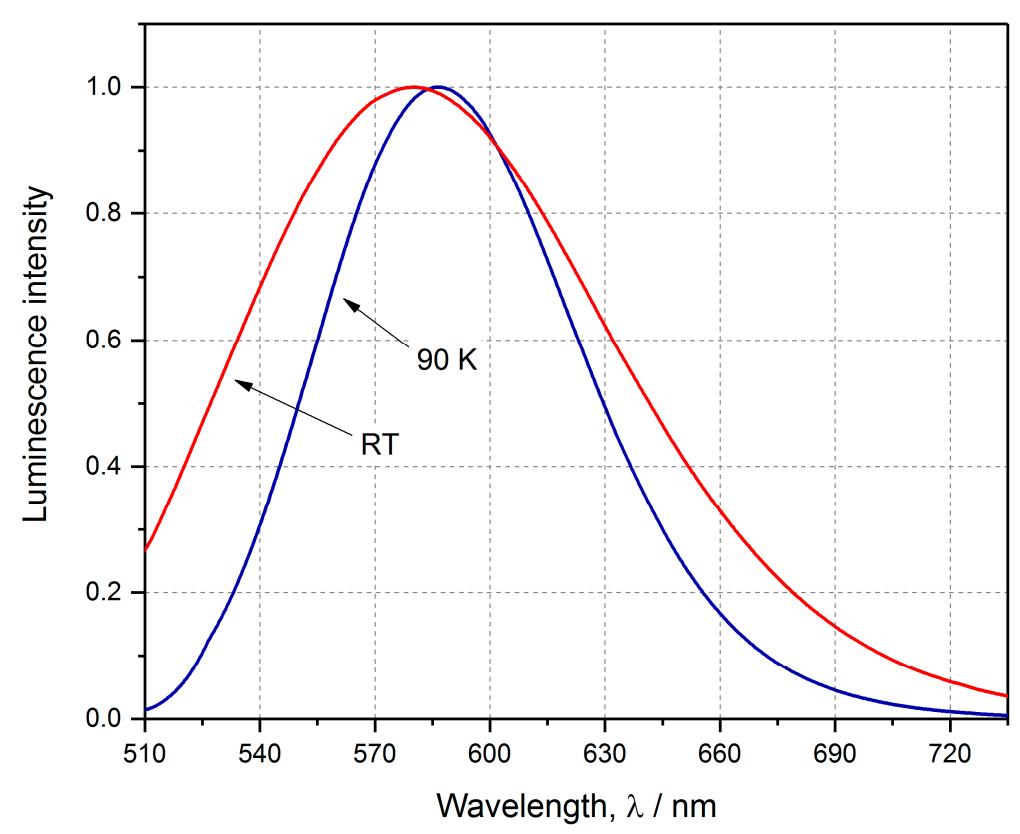

Figure 4. Emission spectra (smoothed and normalised) recorded for the $\mathbf{C u}_{6}$ crystal forms at $90 \mathrm{~K}$ and RT (excitation wavelength, $\lambda_{\mathrm{ex}}=355 \mathrm{~nm}$ ).

Table 4. The $\mathbf{C u}_{6}$ complex solid-state luminescence lifetimes $(\tau)$ and emission peak maxima $\left(\lambda_{\mathrm{em}}\right)$ obtained from the least-squares fit at various temperatures $(T) . \tau_{1}$ and $\tau_{\mathrm{s}}$ denote longer and shorter lifetime, respectively.

\begin{tabular}{cccc}
\hline $\boldsymbol{T} / \mathbf{K}$ & $\tau_{\mathbf{s}} / \boldsymbol{\mu s}$ & $\tau_{\mathbf{l}} / \boldsymbol{\mu s}$ & $\lambda_{\mathbf{e m}} / \mathbf{n m}$ \\
\hline 90 & $17.4(4)$ & $117.9(7)$ & 586 \\
$\mathrm{RT}^{a}$ & $13.0(4)$ & $79.0(3)$ & 577 \\
\hline
\end{tabular}

${ }^{a}$ RT-room temperature.

Finally, it should be noted that significant Stokes shift and relatively long emission decay times ( $\mu$ s regime) observed for the studied complexes' crystals, i.e., $\mathbf{C} \mathbf{u}_{4}$ and $\mathbf{C} \mathbf{u}_{6}$, suggest that in both cases, the emissive state is of triplet nature.

\subsection{Theoretical Modelling}

For the purpose of the described emission bands' nature investigation, theoretical modelling and computations were performed. At first, it was checked how the ground state optimised molecular geometries compare to those found in the crystal lattice. The ground-state geometry optimizations were conducted using crystal structures as a starting point. Two approaches were compared, i.e., optimization of a single $\mathbf{C} \mathbf{u}_{4}$ moiety in the gas phase and optimization of both $\mathrm{Cu}_{4}$ molecules forming the asymmetric unit in the QM/MM approach using the ONIOM electronic embedding to emulate the effect of the crystal environment. The results of theoretical calculations are shown in Table 5, and in the Supplementary Materials. 
Table 5. Selected distances and angles for $\mathrm{Cu}_{4}$ : in ground state $\left(\mathrm{S}_{0}\right)$ : comparison of experiment and theory. $90 \mathrm{~K}$ denotes experimental results (Table 1); QM/MM denotes modelled solid-state structures; CAM-B3LYP denotes theoretical isolated-molecule results (shown only once for molecule A entries).

\begin{tabular}{|c|c|c|c|c|}
\hline Molecule & Bond Distance, $d / \AA ̊$ & $90 \mathrm{~K}$ & $\mathrm{QM} / \mathrm{MM}$ & CAM-B3LYP \\
\hline \multirow[t]{10}{*}{ A } & $\mathrm{Cu} 1-\mathrm{Cu} 3$ & $2.7061(9)$ & 2.735 & 2.738 \\
\hline & $\mathrm{Cu} 1-\mathrm{Cu} 4$ & $2.7335(7)$ & 2.722 & $2.738 *$ \\
\hline & $\mathrm{Cu} 2-\mathrm{Cu} 3$ & $2.7129(7)$ & 2.734 & $2.738 *$ \\
\hline & $\mathrm{Cu} 2-\mathrm{Cu} 4$ & $2.7325(9)$ & 2.758 & $2.738 *$ \\
\hline & $\mathrm{Cu} 1 \cdots \mathrm{Cu} 2^{¥}$ & $2.8726(8)$ & 2.846 & 2.911 \\
\hline & $\mathrm{Cu} 3 \cdots \mathrm{Cu} 4 \ddagger$ & $4.622(1)$ & 4.677 & 4.638 \\
\hline & $\mathrm{Cu} 1-\mathrm{O} 1$ & $1.867(1)$ & 1.872 & 1.853 \\
\hline & $\mathrm{Cu} 2-\mathrm{O} 8$ & $1.876(1)$ & 1.881 & $1.853 *$ \\
\hline & $\mathrm{Cu} 3-\mathrm{O} 7$ & $1.844(1)$ & 1.843 & 1.844 \\
\hline & $\mathrm{Cu} 4-\mathrm{O} 2$ & $1.855(2)$ & 1.851 & $1.844^{*}$ \\
\hline \multirow[t]{10}{*}{ B } & $\mathrm{Cu} 5-\mathrm{Cu} 7$ & $2.7256(9)$ & 2.690 & - \\
\hline & $\mathrm{Cu} 5-\mathrm{Cu} 8$ & $2.7025(7)$ & 2.704 & - \\
\hline & $\mathrm{Cu} 6-\mathrm{Cu} 7$ & $2.7118(7)$ & 2.746 & - \\
\hline & $\mathrm{Cu} 6-\mathrm{Cu} 8$ & $2.7113(9)$ & 2.732 & - \\
\hline & $\mathrm{Cu} 5 \cdots \mathrm{Cu} 6^{¥}$ & $3.0797(9)$ & 3.128 & - \\
\hline & $\mathrm{Cu} 7 \cdots \mathrm{Cu} 8 \ddagger$ & $4.4668(8)$ & 4.445 & - \\
\hline & Cu5 . O 16 & $1.855(1)$ & 1.854 & - \\
\hline & Cu6 $\cdots$ O11 & $1.852(2)$ & 1.853 & - \\
\hline & Cu7...O15 & $1.864(1)$ & 1.868 & - \\
\hline & Cu8 . O O12 & $1.864(1)$ & 1.865 & - \\
\hline Molecule & Valence Angle, $\theta /^{\circ}$ & $90 \mathrm{~K}$ & QM/MM & CAM-B3LYP \\
\hline \multirow[t]{4}{*}{$\mathrm{A}$} & $\mathrm{Cu} 3-\mathrm{Cu} 1-\mathrm{Cu} 4$ & $116.37(2)$ & 117.97 & 115.77 \\
\hline & $\mathrm{Cu} 3-\mathrm{Cu} 2-\mathrm{Cu} 4$ & $116.17(2)$ & 116.76 & 115.77 \\
\hline & $\mathrm{Cu} 1-\mathrm{Cu} 3-\mathrm{Cu} 2$ & $64.03(2)$ & 62.71 & 64.23 \\
\hline & $\mathrm{Cu} 1-\mathrm{Cu} 4-\mathrm{Cu} 2$ & $63.41(2)$ & 62.56 & 64.23 \\
\hline \multirow[t]{4}{*}{ B } & $\mathrm{Cu} 7-\mathrm{Cu} 5-\mathrm{Cu} 8$ & $110.75(2)$ & 111.00 & - \\
\hline & $\mathrm{Cu} 7-\mathrm{Cu} 6-\mathrm{Cu} 8$ & $110.91(2)$ & 108.47 & - \\
\hline & $\mathrm{Cu} 5-\mathrm{Cu} 7-\mathrm{Cu} 6$ & $69.00(2)$ & 70.26 & - \\
\hline & $\mathrm{Cu} 5-\mathrm{Cu} 8-\mathrm{Cu} 6$ & $69.34(2)$ & 70.27 & - \\
\hline
\end{tabular}

${ }^{¥}$ Short diagonal. ${ }^{\ddagger}$ Long diagonal. ${ }^{*}$ These bonds are identical in the gas-phase-optimised molecule.

In general, the agreement between the experiment and theory appears to be satisfactory. Both tested range-separated functionals, $\omega B$ 97XD and CAM-B3LYP, yielded similar optimised gas-phase geometry of the ${ }^{1} \mathrm{~A}$ ground state exhibiting the $D_{2}$ symmetry (222 in crystallographic notation), which closely resembles the experimental geometries. In turn, $\mathrm{QM} / \mathrm{MM}$ correctly imitates distortions from the $D_{2}$ symmetry of both independent molecules constituting the asymmetric unit (the $\mathrm{A}$ and $\mathrm{B}$ molecules), including different shapes of the Cu4-cores. The most significant differences between the gas phase and QM/MM results, however, concern the organic ligands, as illustrated in Figure 5.

Having received the above overview of the approach and functional performance for the ground-state of $\mathbf{C u}_{4}$, lowest excited states of the studied complex were derived using the TDDFT method. Table 6 presents the first ten triplet excited states calculated for the $\mathbf{C u}_{4}$ species, both in the gas phase and in the molecular environment. 


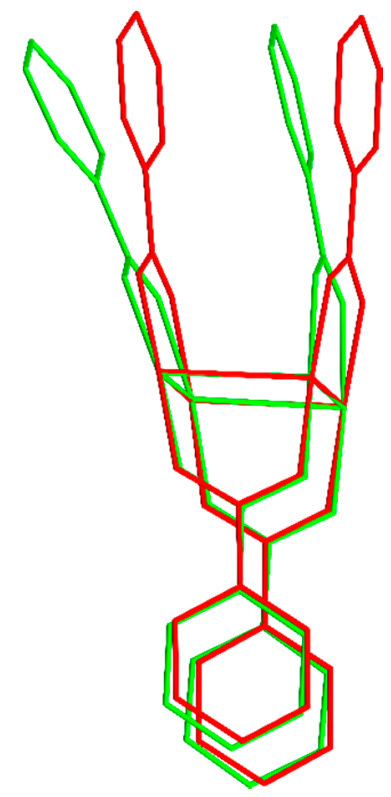

(a)

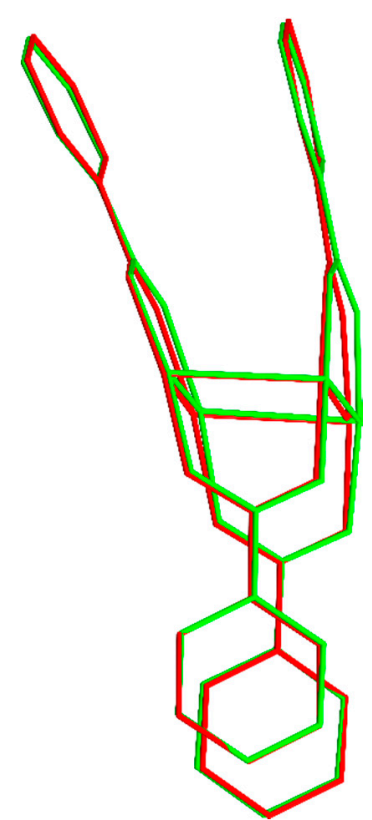

(b)

Figure 5. Overlay of the ground state geometries $\left(\mathrm{S}_{0}\right)$ : experimental (green colour) and DFT-optimised (red colour) geometries for (a) isolated-molecule and (b) QM/MM theoretical results. (hydrogen atoms are omitted for clarity; figures shown only for molecule A; in the (a) panel the molecular cores are least-squares superimposed).

Table 6. Lowest-energy triplet excited states computed for a single $\mathbf{C u}_{4}$ molecule for both the isolated molecule and QM/MM results. Symmetry labels refer to the isolated-molecule CAM-B3LYP results for the complex exhibiting $D_{2}$ point-group symmetry.

\begin{tabular}{cccc}
\hline \multirow{2}{*}{ State } & \multicolumn{3}{c}{ Method \& Excitation Energy/eV } \\
\cline { 2 - 4 } & CAM-B3LYP (isol.) & QM/MM (mol. A) & QM/MM (mol. B) \\
\hline $1^{3} \mathrm{~A}$ & 3.12 & 3.21 & 3.16 \\
$1^{3} \mathrm{~B}_{1}$ & 3.27 & 3.32 & 3.35 \\
$1^{3} \mathrm{~B}_{2}$ & 3.27 & 3.35 & 3.36 \\
$2^{3} \mathrm{~A}$ & 3.28 & 3.36 & 3.37 \\
$1^{3} \mathrm{~B}_{3}$ & 3.28 & 3.37 & 3.37 \\
$2^{3} \mathrm{~B}_{1}$ & 3.32 & 3.39 & 3.46 \\
$2^{3} \mathrm{~B}_{2}$ & 3.55 & 3.65 & 3.57 \\
$3^{3} \mathrm{~A}$ & 4.12 & 4.12 & 4.14 \\
$2^{3} \mathrm{~B}_{3}$ & 4.15 & 4.22 & 4.16 \\
$3^{3} \mathrm{~B}_{1}$ & 4.23 & 4.26 & 4.23 \\
\hline
\end{tabular}

The excitation energies obtained for the isolated complex in the $D_{2}$ symmetry are comparable to these derived for the embedded complexes with distorted-core geometries. The first excited ${ }^{3} \mathrm{~A}$ state involves excitations from HOMO, HOMO-1, and HOMO-2 to LUMO and several higher-lying orbitals. The frontier molecular orbitals of $\mathbf{C u}_{4}$ are shown in Figure 6, i.e., $\mathrm{HOMO}$ of the antibonding character and the bonding LUMO (see also Figure S5). As indicated by the orbital population analysis, both the initial and final molecular orbitals are composed mainly of copper d orbitals, which suggests that ${ }^{3} \mathrm{~A}$ has a distinct cluster-centred character. Directly above $1^{3} \mathrm{~A}$, there is a set of close-lying excited states, three of the ${ }^{3} \mathrm{~B}$ symmetry and one of the ${ }^{3} \mathrm{~A}$ symmetry. The corresponding excitation amplitudes are distributed among configurations of a ligand-ligand and core-ligand character. 


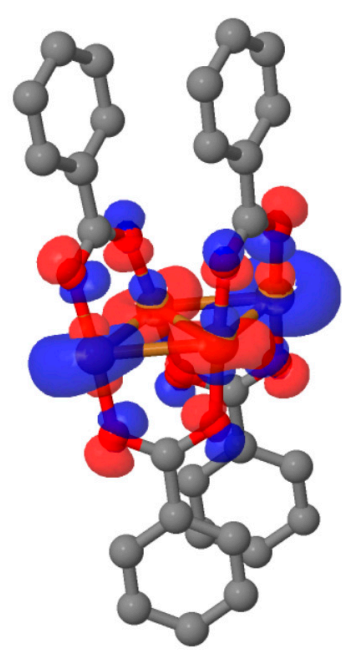

(a)

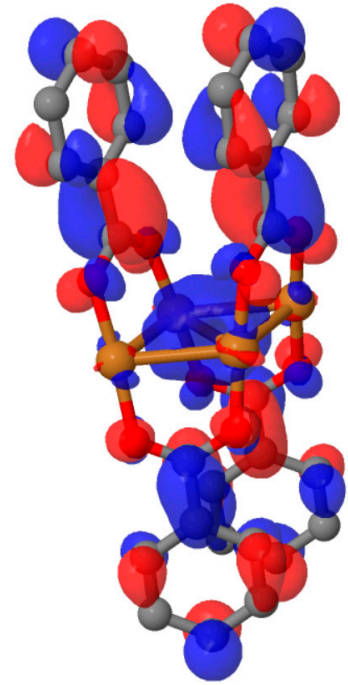

(b)

Figure 6. Frontier molecular orbitals of the $\mathrm{Cu}_{4}$ complex (isosurfaces drawn at \pm 0.04 a.u.; blue-positive; red-negative) obtained at the CAM-B3LYP/cc-pVDZ level of theory: (a) HOMO, (b) LUMO.

To gain insight into the nature of the computed excited states, the one-particle transition density matrix (1-TDM) obtained at the TDDFT level of theory was analysed. In particular, the concept of charge transfer numbers introduced by Plasser \& Lishka [31] was employed, as well as its extension to a transition-metal complex case [32]. When two molecular fragments A and B are considered, the charge transfer number is defined as:

$$
\Omega_{\mathrm{AB}}=\frac{1}{2} \sum_{\mu \in \mathrm{A}} \sum_{v \in \mathrm{B}}\left[\left(\mathbf{D}^{0 I} \mathbf{S}\right)_{\mu \nu}\left(\mathbf{S D}^{0 I}\right)_{\mu \nu}+D_{\mu \nu}^{0 I}\left(\mathbf{S D}^{0 I} \mathbf{S}\right)_{\mu \nu}\right]
$$

where the sum runs over all atomic basis functions $\mu$ and $v$ on fragments $\mathrm{A}$ and $\mathrm{B}$, respectively. $\mathbf{D}^{0 I}$ stands for 1-TDM, while $\mathbf{S}$ is the overlap matrix. The total charge transfer (CT) character is given as the sum of the off-diagonal elements of the CT matrix:

$$
\omega_{\mathrm{CT}}=\frac{1}{\Omega} \sum_{\mathrm{B} \neq \mathrm{A}} \Omega_{\mathrm{AB}}
$$

where the $\Omega=\sum_{\mathrm{AB}} \Omega_{\mathrm{AB}}$ normalization factor corresponds to the squared norm of 1-TDM. The matrix can be visualized in a direct manner yielding the so-called electron-hole correlation plots $(\Omega$-matrix plots) [49]. The $\omega_{\mathrm{CT}}$ index may be partitioned into metal centred (MC), ligand centred (LC), metal-to-ligand (MLCT), ligand-to-metal (LMCT), and ligand-to-ligand (LLCT) charge-transfer contributions [32]. Consequently, the total CT index can be expressed as follows: $\omega_{\mathrm{CT}}=\omega_{\mathrm{MLCT}}+$ $\omega_{\mathrm{LMCT}}+\omega_{\mathrm{LLCT}}$. For the purpose of the described analysis, a single $\mathbf{C} \mathbf{u}_{4}$ molecule was divided into five fragments, i.e., the $\mathbf{C u}_{4}$ metal core and four benzoic acid ligands. In Figure 7 the obtained electron-hole correlation plots for the first ten triplet excited states of the gas-phase-optimised $\mathbf{C u}_{4}$ complex are presented, while Table S3 contains the corresponding excitation energies and the 1-TDM analysis results. 
$1^{3} \mathrm{~A}, \omega_{\mathrm{CT}}=0.26$

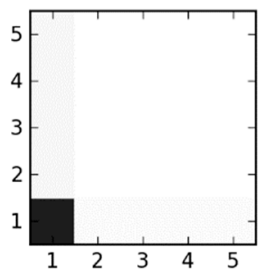

$2^{3} \mathrm{~B}_{1}, \omega_{\mathrm{CT}}=0.23$

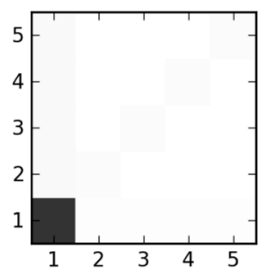

$1^{3} \mathrm{~B}_{1}, \omega_{\mathrm{CT}}=0.05$

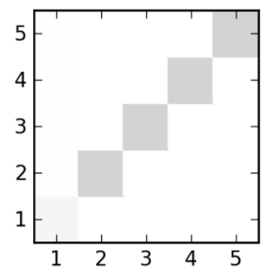

$1^{3} \mathrm{~B}_{2}, \omega_{\mathrm{CT}}=0.00$

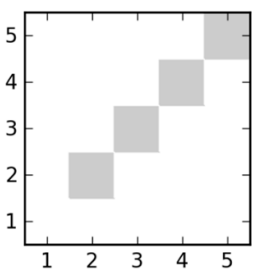

$3^{3} \mathrm{~A}, \omega_{\mathrm{CT}}=0.17$

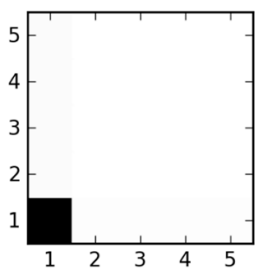

$2^{3} \mathrm{~A}, \omega_{\mathrm{CT}}=0.00$
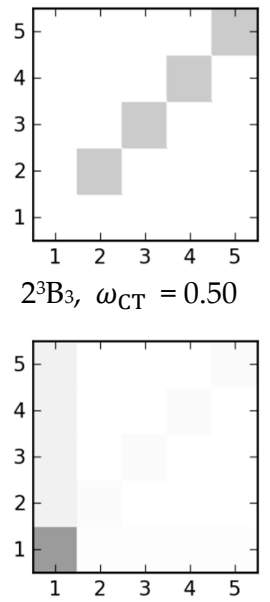

$1^{3} \mathrm{~B}_{3}, \omega_{\mathrm{CT}}=0.00$

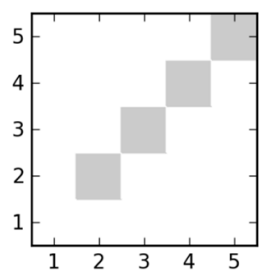

$3^{3} \mathrm{~B}_{1}, \omega_{\mathrm{CT}}=0.26$

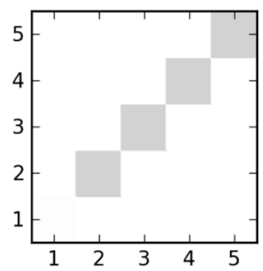

Figure 7. Electron-hole correlation plots ( $\Omega$-matrix plots) for the first ten triplet excited states of $\mathbf{C u}_{4}$ in the $D_{2}$ symmetry (CAM-B3LYP/VDZ results). Fragment 1 corresponds to the $\mathbf{C} \mathbf{u}_{4}$ core, fragments $2-5$ denote the benzoic acid ligands.

Based on the information from 1-TDM, it can be concluded that two types of triplet states are distinguishable. The first type gathers the core-centred states with significant contributions from the metal-to-ligand charge-transfer excitations. The second type includes states of Frenkel exciton nature involving $\pi \rightarrow \pi^{*}$ excitation localised on the ligands (Figure 7).

In this view, the lowest-lying ${ }^{3} \mathrm{~A}$ triplet together with states from 6 th to $9^{\text {th }}$ can be classified as the first type, i.e., they all share the dominant core-centred character, which is reflected in the notable $\omega_{\mathrm{MC}}$ values ranging from 0.7 to 0.8 , and in the MLCT contributions being above 0.1 . The mixed charge transfer character is also supported by the number of participating fragments (referred to as PR) ranging between 1.21 and 2.56. The largest $C T$ index, indicated by grey off-diagonal elements in the $\Omega$-matrix plot (Figure 7), is observed for the 9 th state. In turn, deviation from the $D_{2}$ symmetry results in a stronger CT character of all these states calculated for the QM/MM geometries, manifested by larger MLCT and LMCT contributions (for details see Table S3). In particular, in the first excited state $\omega_{\text {MLCT }}$ amounts to 0.202 , whereas it equals 0.165 in the $D_{2}$ case. The delocalisation of the excitation from the complex's core to one of the ligands affects also the PR value, which increases from 1.3 to 2.0.

The second type of triplet states encompasses states from the 2nd to 5 th, as well as, the 10th triplet state. The local character of these excitations can be deduced from the electron-hole correlation plots dominated by diagonal elements, the $\omega_{\mathrm{CT}}$ values being close to zero, and the number of participating fragments around 3.5 (Figure 7, Table S3).

The nature of excited states may also be analysed by inspection of natural transition orbitals (NTOs). NTOs are obtained from the singular value decomposition of 1-TDM:

$$
\mathbf{D}^{0 I,[\mathrm{MO}]}=\mathbf{U} \cdot \operatorname{diag}\left(\sqrt{\lambda_{1}}, \sqrt{\lambda_{2}}, \ldots\right) \cdot \mathbf{V}^{T}
$$

where matrices $\mathbf{U}$ and $\mathbf{V}$ contain hole (initial) and particle (final) orbitals, respectively. The advantage of NTOs over canonical orbitals is that the former provide a more compact representation of the excitation, i.e., typically only a few configurations are needed to describe the electronic transition. In Figure 8 we present the dominant NTO pairs for the $1^{3} \mathrm{~A}$ and $1^{3} \mathrm{~B}_{1}$ states. Examination of NTOs corroborates the character of triplet excitations as deduced from the $\Omega$-matrix plots. In the ${ }^{3} \mathrm{CC}$ states the electron and hole are localised primarily in the core region, and the antibonding-to-bonding transition is clearly visible. The contributions from $2 p$ orbitals of oxygen atoms correspond to the MLCT transitions. In turn, visual inspection of NTOs computed for the $1^{3} B_{1}$ state confirms the $\pi \rightarrow \pi^{*}$ character of excitations localised on the benzoic acid fragments. 
State $1^{3} \mathrm{~A}$

Hole

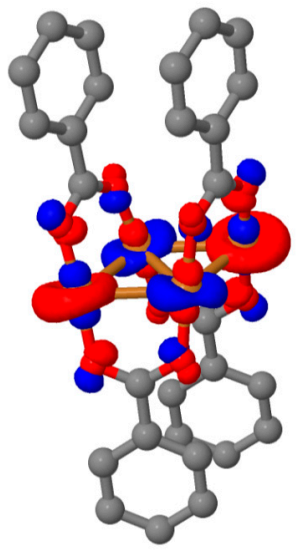

$\lambda_{i}=0.77$

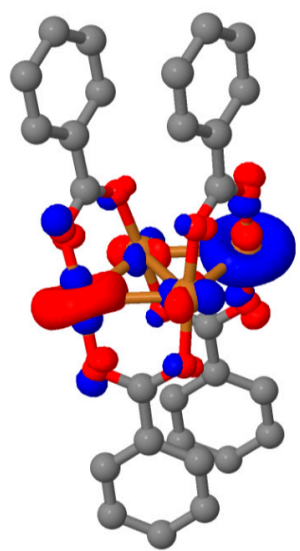

$\lambda_{i}=0.13$

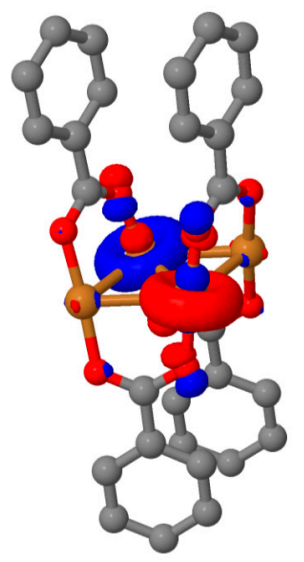

$\lambda_{i}=0.10$
Particle

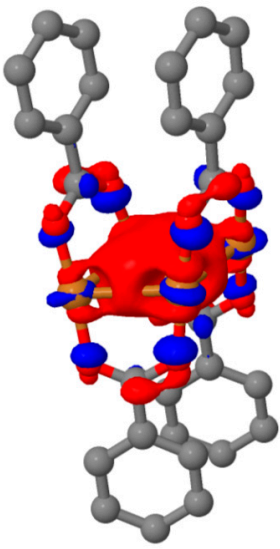

$\lambda_{i}=0.77$

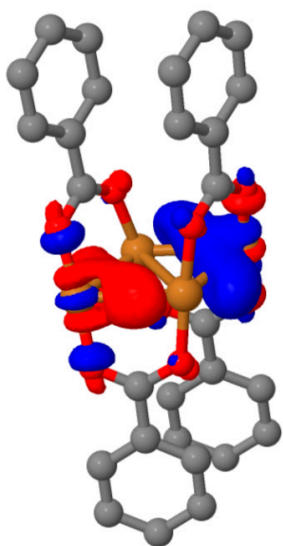

$\lambda_{i}=0.13$

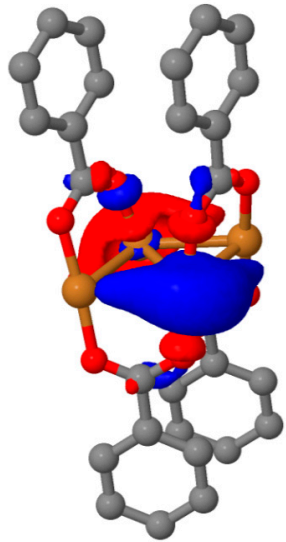

$\lambda_{i}=0.10$
State ${ }^{3} \mathrm{~B}_{1}$

Hole

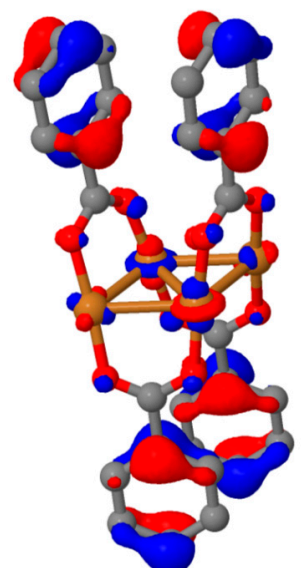

$\lambda_{i}=0.23$

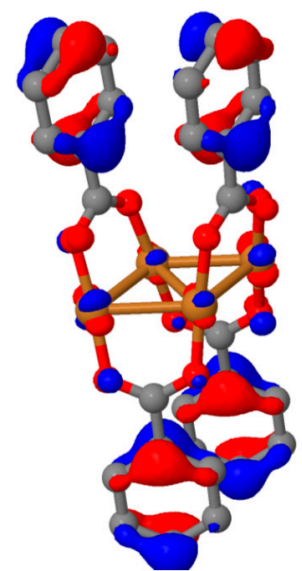

$\lambda_{i}=0.21$

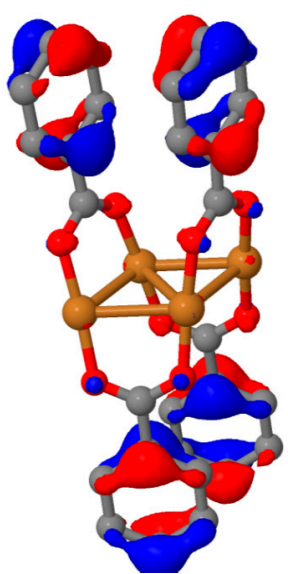

$\lambda_{i}=0.13$
Particle

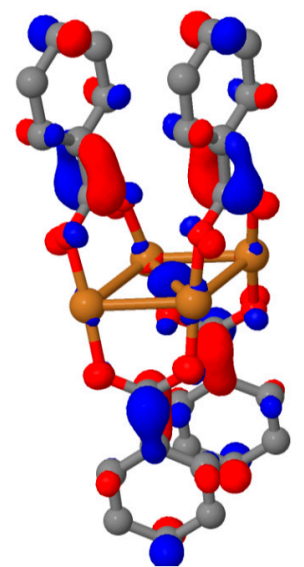

$\lambda_{i}=0.23$

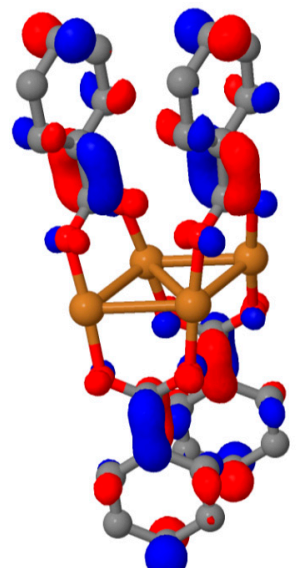

$\lambda_{i}=0.21$

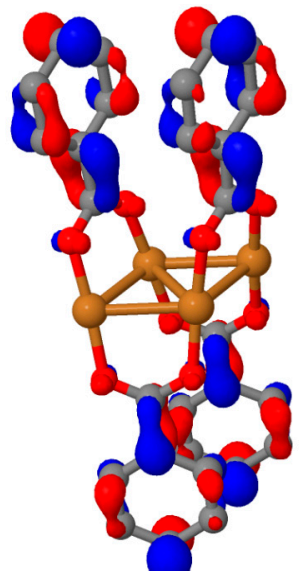

$\lambda_{i}=0.13$

Figure 8. Dominant hole and particle NTOs $\left(\lambda_{i} \geq 0.1\right)$ for the $1^{3} \mathrm{~A}$ and $1^{3} \mathrm{~B}_{1}$ states of $\mathbf{C u}_{4}$ (isosurfaces drawn at \pm 0.04 a.u.; blue-positive; red-negative) obtained at the CAM-B3LYP/cc-pVDZ level of theory.

Finally, to model the most probable structural changes occurring during the excitation, two lowest-lying triplets were optimised using the analytic gradients from the TDDFT calculations. The selected optimised geometrical parameters are presented in Table 7. The calculations were carried 
out both in the gas phase and in the crystal environment, where possible. In each case, frequency calculations confirmed the presence of the minima. The first excited $\mathrm{T}_{1}$ state structures obtained in different approaches remain in close agreement. The second excited state, denoted as $T_{2}$, was determined only for the $D_{2}$ symmetry (gas phase) $\mathbf{C u}_{4}$ complex. The $\mathrm{T}_{2}$ optimisation was conducted using two approaches, which led to identical results, i.e., either by converging the 6th root in TDDFT, or by optimisation of the unrestricted Kohn-Sham (UKS) determinant with a deformed $\mathbf{C u}_{4}$-core as a starting point. It was not possible to reach the excited state minima corresponding to the $\pi \rightarrow \pi^{*}$ excitations, for which geometrical changes should occur primarily on the organic parts of the ligands.

Table 7. Comparison of selected ground $\left(\mathrm{S}_{0}\right)$ and excited triplet-state $\left(\mathrm{T}_{1} \& \mathrm{~T}_{2}\right)$ geometries. QM/MM denotes modelled solid-state structures; CAM-B3LYP denote theoretical isolated-molecule results (shown only once for molecule A entries). See also Figures S3 and S4 in the Supplementary Materials.

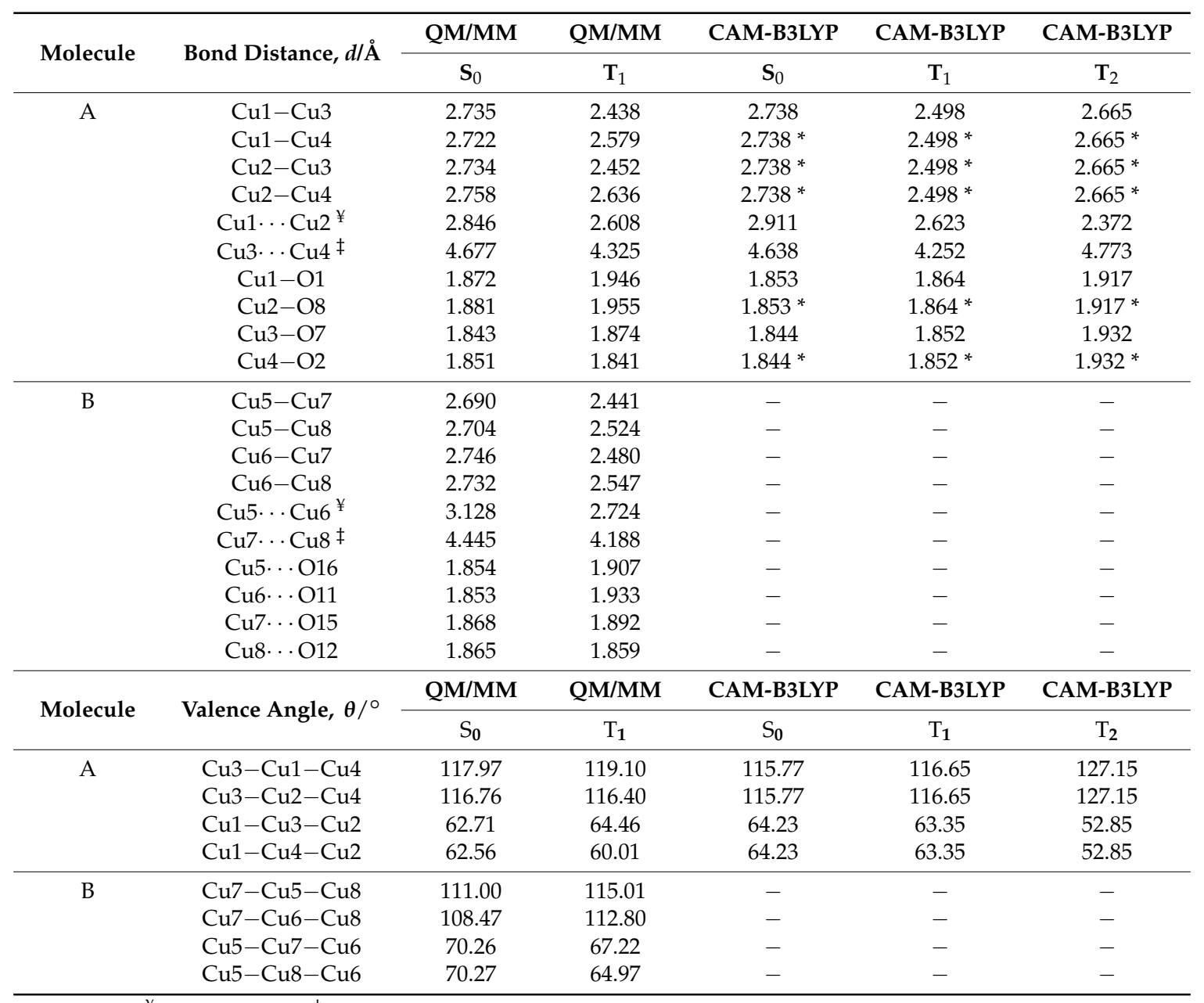

${ }^{¥}$ Short diagonal. ${ }^{\ddagger}$ Long diagonal. * All bonds are identical because the molecule is symmetric.

It appeared that both $\mathrm{T}_{1}$ and $\mathrm{T}_{2}$ states involve significant changes in the $\mathbf{C u}_{4}$ core compared to $\mathrm{S}_{0}$ (Table 7, Figure S3), which is consistent with the ${ }^{3} \mathrm{CC}$ character of the first and 6th excited states predicted from the 1-TDM analysis (Figures 7 and 8). Among these, the core contraction was estimated to be notably larger for the $\mathrm{S}_{0} \rightarrow \mathrm{T}_{1}$ transition, for which the $\mathrm{Cu}-\mathrm{Cu}$ distance is shortened by $0.240 \AA$ upon excitation (for the gas-phase-optimised $\mathbf{C u}_{4}$ geometries; for $\mathrm{T}_{2}$ it is shortened by $0.073 \AA$; Table 7 ). In the case of $T_{2}$, the changes in the metal core were predicted to be smaller, however, more significant elongation of the $\mathrm{Cu}-\mathrm{O}$ bonds with respect to the $\mathrm{S}_{0}$ state was observed (1.93 $\AA$ vs. $1.85 \AA$, respectively; Table 7). This finding supports the presence of non-negligible MLCT and/or LMCT contribution to the ${ }^{3} \mathrm{CC}$ state. 
The TDDFT excitation energies from the ground state to the first triplet state (referred to as 1st $\mathrm{S}_{0} \rightarrow \mathrm{T}$ ) calculated for the optimised geometries of the $\mathrm{S}_{0}, \mathrm{~T}_{1}$, and $\mathrm{T}_{2}$ states are gathered in Table 8 . Additionally, the $\triangle \mathrm{SCF}$ values, i.e., the difference between the electronic energy of the triplet state and the energy of respective singlet states (both energies calculated at the triplet minimum-energy geometry), are reported. In the case of the $\mathrm{T}_{1}$ geometry, the lowest triplet excited state occurs at $1.952 \mathrm{eV}$ $(635 \mathrm{~nm}$ ), while the corresponding $\triangle \mathrm{SCF}$ value is equal to $592 \mathrm{~nm}$. The $\mathrm{QM} / \mathrm{MM}$ calculations predicted this state at $2.077 \mathrm{eV}(597 \mathrm{~nm})$ for the A molecule, while at $2.001 \mathrm{eV}(618 \mathrm{~nm})$ for B. The emission from the $\mathrm{T}_{1}$ state computed using the TDDFT approach matches the experimental low-energy band observed at $660-715 \mathrm{~nm}$. The identification of the second emitting state is less straightforward. In the case of the $\mathrm{T}_{2}$ geometry the lowest triplet state was placed by TDDFT at $2.149 \mathrm{eV}(578 \mathrm{~nm})$, while the $\triangle \mathrm{SCF}$ amounted to $523 \mathrm{~nm}$. Thus, the anticipated emission from $\mathrm{T}_{2}$ in the $\mathrm{D}_{2}$ symmetry is close to the experimental value of $546 \mathrm{~nm}$. It should be noted, however, that upon distortion of the $D_{2}$ symmetry, which is observed in crystals, as well as in the QM/MM-optimized structures, the two types of states gain significantly more MLCT and LMCT contributions. Furthermore, it was not possible to identify a minimum on the excited potential energy surfaces complying with the states dominated by the $\pi \rightarrow \pi^{*}$ excitations.

Table 8. The TDDFT-computed excitation energies from the ground state to the first triplet state calculated for the optimised geometries of the $S_{0}, T_{1}$, and $T_{2}$ states. CAM-B3LYP denotes theoretical isolated-molecule results, and QM/MM denotes modelled solid-state structures; $\triangle \mathrm{SCF}$ is the difference between the electronic energy of the triplet state and energy singlet states (both calculated at the triplet minimum-energy geometry).

\begin{tabular}{ccccc}
\hline Method & State & $1^{\text {st }} \mathbf{S}_{0} \rightarrow \mathbf{T} / \mathbf{e V}$ & $1^{\text {st }} \mathbf{S}_{0} \rightarrow \mathbf{T} / \mathbf{n m}$ & $\Delta \mathbf{S C F} / \mathbf{n m}$ \\
\hline CAM-B3LYP (isol.) & $\mathrm{T}_{1}\left(1^{3} \mathrm{~A}\right)$ & 1.952 & 635 & 592 \\
CAM-B3LYP (isol.) & $\mathrm{T}_{2}\left(2^{3} \mathrm{~B}_{1}\right)$ & 2.149 & 578 & 523 \\
QM/MM (mol. A) & $\mathrm{T}_{1}$ & 2.077 & 597 & - \\
QM/MM (mol. B) & $\mathrm{T}_{1}$ & 2.001 & 618 & - \\
\hline
\end{tabular}

\subsection{Time-Resolved X-ray Laue Diffraction Results}

Determination of geometry changes occurring in the $\mathbf{C u}_{4}$ complex in the crystal form at $90 \mathrm{~K}$ and $225 \mathrm{~K}$ upon excitation may provide us some indication about the nature of the dominant excited states at low and high temperatures. This goal can be realised via a time-resolved laser-pump/X-ray-probe Laue technique, especially for heavier atoms rich in electrons [50]. Nevertheless, even some information on the copper core deformation would be of help, as the changes in the cluster-centre geometry confronted with the theoretical results could give us premises about the emission origins.

In the studied case, the full response-ratio refinement [51] was unfortunately not possible, most probably due to the rather low completeness of the collected data $(35 \%$ and $17 \%$ for $90 \mathrm{~K}$ and $225 \mathrm{~K}$ data, respectively), as a result of low conversion, low space-group symmetry of the sample and the examined crystals' shape. Nevertheless, some meaningful qualitative conclusions can still be drawn. The obtained photodifference maps, computed for the copper cores, are presented in Figure 9. The negative peaks, as expected, are localised on copper atoms' positions, which shows that these atoms shifted/moved upon excitation. The similarity of photodifference maps obtained from two independent measurements at both 90 and $225 \mathrm{~K}$ is striking. This suggests the same excited state was captured in both experiments and also indicates good reproducibility of the results. Since the pump-probe delay was set to several ns, while the studied excited state lifetimes are in the $\mu$ s regime (Table 3), such explanation is rational. The measurement could have been faster than the conversion to the final emissive state. In such a case, either some singlet excited state was captured, or the high-energy ("green") triplet excited state. It also seems that most of the peaks are located closer to the centre of the cluster core, especially for molecule B (see, e.g., the large peak next to the Cu7 atom), which suggests its contraction. For this molecule, more peaks are visible than for A when 
the same isocontour values are applied. This suggests that the molecule B, exhibiting longer "short" diagonal $\mathrm{Cu} \cdot \mathrm{Cu}$ contact, should undergo more pronounced core contraction when excited, which is indeed observed in the $\mathrm{T}_{1} \mathrm{QM} / \mathrm{MM}$ results. Nevertheless, the experimental geometrical changes are not straightforward. Regarding the theoretical results, one may conclude that the low-energy excited state should be characterised by more significant changes of the copper core shape which becomes more quadratic (Table 7), whereas the high-energy excited state is expected to exhibit more emphasized $\mathrm{Cu}-\mathrm{O}$ bond elongation and less notable copper atoms' distortions from the GS geometry (Supplementary Materials). For both $\mathrm{T}_{1}$ and $\mathrm{T}_{2}$ states, the contraction of all $\mathrm{Cu}-\mathrm{Cu}$ bonds is observed and also the shorter diagonal gets contracted (Table 7).

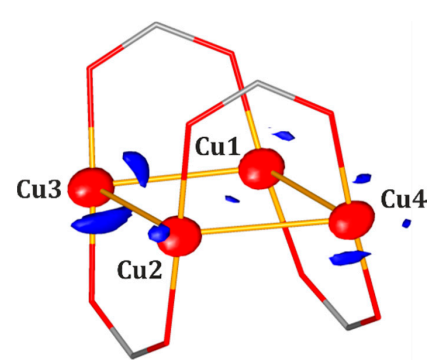

(a)

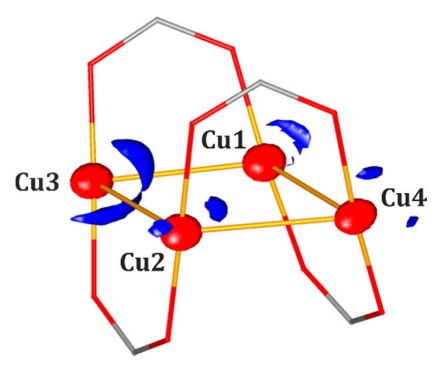

(c)

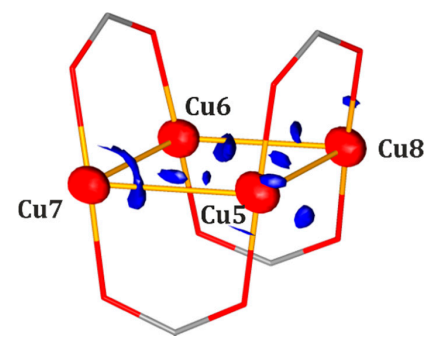

(b)

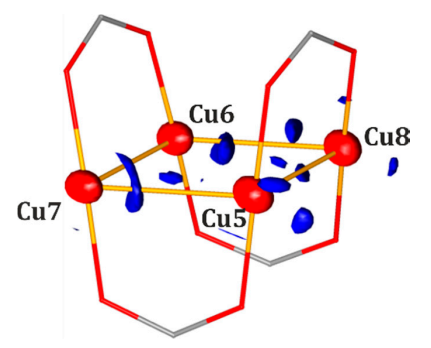

(d)

Figure 9. Photodifference maps $\left(F_{\mathrm{O}}^{\mathrm{ON}}-F_{\mathrm{O}}^{\mathrm{OFF}}\right)$ drawn for $90 \mathrm{~K}(\mathbf{a}, \mathbf{b})$ and $225 \mathrm{~K}(\mathbf{c}, \mathbf{d})$ time-resolved Laue data collections: $(\mathbf{a}, \mathbf{c})$ molecule $\mathrm{A},(\mathbf{b}, \mathbf{d})$ molecule $\mathrm{B}$. Blue isosurface-positive, red-negative $\left(-2.0 \mathrm{e} \cdot \AA^{-3} \&+0.9 \mathrm{e} \cdot \AA^{-3}\right.$, and $-1.5 \mathrm{e} \cdot \AA^{-3} \&+0.5 \mathrm{e} \cdot \AA^{-3}$ for top and bottom panels, respectively); only selected atoms are shown for clarity.

\section{5. $\mathrm{Cu}_{4}$ and $\mathrm{Cu}{ }_{6}$ Comparison}

As already mentioned, despite the similarity of $\mathbf{C u}_{4}$ and $\mathbf{C} \mathbf{u}_{6}$, no luminescence thermochromism was observed in the latter case. In an attempt to explain such behaviour, the first few excited states of the $\mathbf{C u}_{6}$ complex were calculated and analysed. It appears that the nature of the first singlet and triplet states obtained for $\mathbf{C} \mathbf{u}_{4}$ and $\mathbf{C u}_{6}$ is qualitatively very much alike. Namely, the triplet states have either a core-centred or ligand-centred character (see the discussion in Section 3.3, and Figures S6, S11 and S12 and Tables S6 and S7), whereas the first singlets are core-centred with significant MLCT charge-transfer contributions (Figures S7, S9 and S10 and Tables S3 and S5). Clearly, without direct probing of the excited-state dynamics, it is not straightforward to establish whether thermochromism occurs for a single $\mathbf{C u}_{4}$ molecule. If this was the case, the lack of this phenomenon in $\mathbf{C u}_{6}$ could be attributed, for instance, to a lower energy barrier between the emissive triplet states. Another possibility is that the thermochromism arises due to crystal packing effects, which are markedly different in the studied structures.

In order to explore the role of molecular packing in the $\mathbf{C u}_{4}$ and $\mathbf{C u}_{6}$ crystals, two closest-neighbour complex molecules were selected in both structures. The lowest-lying excited triplet states of such $\mathbf{C u}_{4}$ and $\mathbf{C u}_{6}$ dimers characterised in terms of natural transition orbitals and electron-hole correlation plots are shown in Figure 10. The dimer geometries were taken directly from the crystal structures. Inspection of Figure 10 reveals different characteristics of the excited states in the 
$\mathbf{C u}_{4}$ and $\mathbf{C \mathbf { u } _ { 6 }}$ dimers. In the former case excitations are localised on the separate monomers, whereas in the latter they are delocalised on both monomers forming exciton resonance states (no charge transfer between the monomers is observed, and each excited state of the $\mathbf{C u}_{6}$ dimer is doubly degenerate). Analogous behaviour was confirmed for singlet states (Figures S8, S13 and S14 and Tables S8 and S9).

(a) $\mathbf{C} \mathbf{u}_{4}$ dimer

Hole

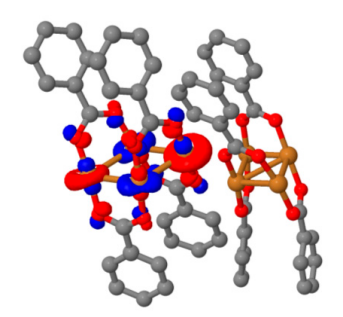

$1^{\text {st }}$ triplet: $\lambda_{i}=0.78$

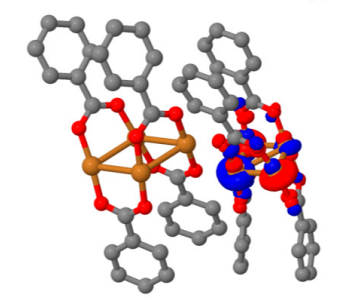

$2^{\text {nd }}$ triplet: $\lambda_{i}=0.81$
Particle
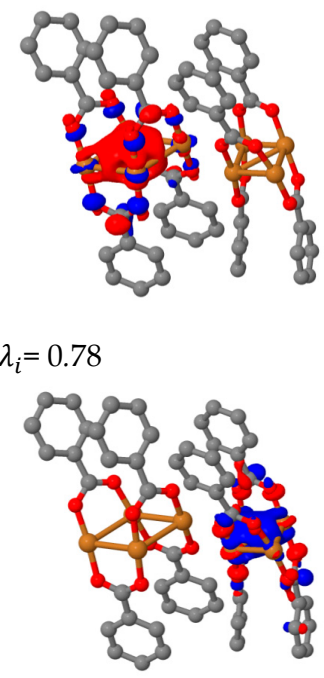

$\mathrm{T}_{1} / 3.146 \mathrm{eV}$

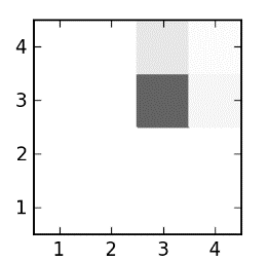

$\mathrm{T}_{2} / 3.185 \mathrm{eV}$

(b) Cú dimer

Hole

Particle

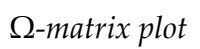
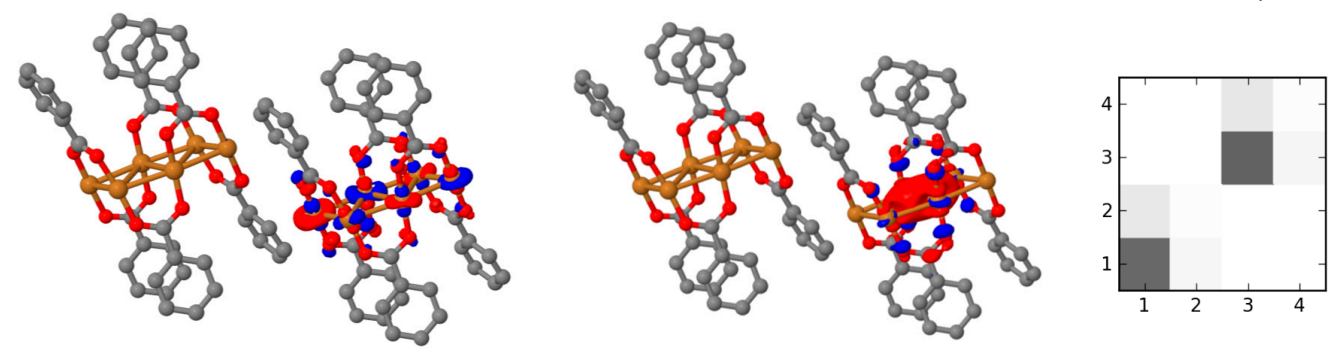

$1^{\text {st }}$ triplet: $\lambda_{i}=0.40$

$\mathrm{T}_{1} / 3.063 \mathrm{eV}$
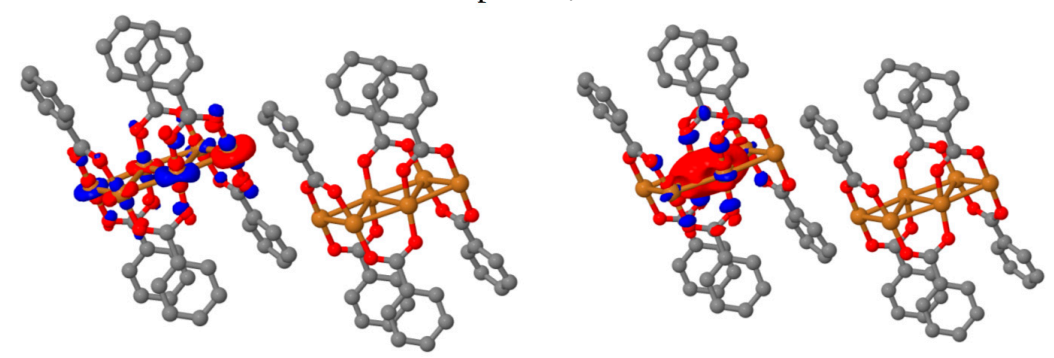

$1^{\text {st }}$ triplet: $\lambda_{i}=0.38$

Figure 10. Dominant NTO pairs and electron-hole correlation plots for $\mathrm{T}_{1}$ and $\mathrm{T}_{2}$ states of the $\mathrm{Cu}_{4}$ dimer (a) and $\mathrm{T}_{1}$ state of the $\mathbf{C u}_{6}$ dimer (b) (isosurfaces drawn at \pm 0.04 a.u.; blue-positive; red-negative) obtained at the CAM-B3LYP/cc-pVDZ level of theory. Fragments 1 and 3 correspond to $\mathrm{Cu}_{n}$ cores, whereas fragments 2 and 4 include all $\mathrm{PhCO}_{2}$ ligands attached to the 1st and 3rd core, respectively. 
The significant difference between the nature of excited states of $\mathbf{C} \mathbf{u}_{4}$ and $\mathbf{C} \mathbf{u}_{6}$ dimers indicates that the distinct spectroscopic behaviour of the two complexes in the solid state could be to some extent attributed to the mutual molecular arrangement in the crystal lattice. Nevertheless, the impact of such intermolecular interactions remains debatable due to the lack of unequivocal evidence on the matter.

\section{Summary and Conclusions}

Although temperature-dependent phosphorescence observed and characterised by us for crystals of the studied tetranuclear copper complex $\mathbf{C u}_{4}$ is similar to the luminescence thermochromism reported for the $\mathrm{Cu}_{4} \mathrm{I}_{4}$-core-containing compounds [52-55], its nature differs substantially between the two systems due to cluster cores chemical and geometrical features. In $\mathrm{Cu}_{4}$, four copper atoms form almost flat parallelogram-like cluster centre instead of a cubane copper-iodine core characteristic for the $\mathrm{Cu}_{4} \mathrm{I}_{4}$-type molecules. In the latter case, the dual emission was attributed to excited states of different character: the low-energy band was assigned to the low-lying emissive ${ }^{3} \mathrm{CC}$ state involving pronounced core geometry relaxation, whereas the high-energy band to a halide-to-ligand charge transfer $\left({ }^{3} \mathrm{XLCT}\right)$ state, in which only minor geometrical changes occur in the core region. In the case of the studied $\mathrm{Cu}^{\mathrm{I}}$ benzoate crystals, a similar low-lying cluster-centred triplet excited state was identified, $\mathrm{T}_{1}$. The emission from the $\mathrm{T}_{1}$ state predicted in TDDFT $(\sim 635 \mathrm{~nm})$ matches the experimental red band observed at $660-715 \mathrm{~nm}$. In contrast, the indication of the high-energy "green" emissive state, active at low temperature, appeared to be much more problematic. First of all, it was not possible to identify a minimum on the excited potential energy surfaces complying with the states dominated by the $\pi \rightarrow \pi^{*}$ excitations, lying directly above the $1^{3} \mathrm{~A}_{1}\left({ }^{3} \mathrm{CC}\right)$ state. The next reached excited state, $\mathrm{T}_{2}$ in the $\mathrm{D}_{2}$ symmetry, occurred energetically close to the experimental value of $546 \mathrm{~nm}$. It should be noted, however, that upon distortion of the $\mathrm{D}_{2}$ symmetry, which is observed in crystals, the two types of states gain significantly more MLCT and LMCT contributions. In both states, $\mathrm{T}_{1}$ and $\mathrm{T}_{2}$, the cluster core is notably contracted when compared to the ground state, which is more emphasised in the case of $\mathrm{T}_{1}$. Photocrystallographic results supported the computationally predicted core contraction upon excitation.

Another issue was the lack of luminescent thermochromism in the case of the related $\mathbf{C u}_{\mathbf{6}}$ crystal structure. Single-molecule computations of the first few excited states provided results analogous to these obtained for $\mathrm{Cu}_{4}$. The differences between the two solid-state systems appeared not until molecular closest dimers from crystal structures were computationally examined. In $\mathrm{Cu}_{6}$, the exciton delocalisation in resonance states was predicted, which was not the case for $\mathbf{C u}_{4}$. Clearly, without direct probing of the excited-state dynamics, it is not straightforward to establish whether thermochromism occurs for a single $\mathrm{Cu}_{4}$ molecule. Furthermore, it would also be very challenging, if at all possible, to verify a single $\mathbf{C} \mathbf{u}_{4}$ or $\mathbf{C} \mathbf{u}_{6}$ molecule's spectroscopic behaviour experimentally. If a single $\mathrm{Cu}_{4}$ cluster is emissive, the lack of this phenomenon in $\mathbf{C u}_{6}$ could be attributed, for instance, to a lower energy barrier between the emissive triplet states. On the other hand, the excited states' delocalisation over dimers expected for $\mathbf{C u}_{6}$ in a crystal lattice could facilitate, or strengthen, the possible transition between the high- and low-energy states, resulting in its shorter time-scale, or enhanced coupling between the excited states, leading to the observed low-energy emission band. Nevertheless, the mechanism behind the luminescent behaviour of the $\mathbf{C} \mathbf{u}_{4}$ and $\mathbf{C u}_{6}$ complexes remains disputable at places due to the lack of unequivocal evidence.

Supplementary Materials: The following are available online at http:/ /www.mdpi.com/2073-4352/9/1/36/s1, Crystal structure data collection and refinement information, additional tables, plots and figures illustrating solution absorption measurements, computed geometries and TDDFT results. CCDC 1878341-46 contain the supplementary crystallographic data for this paper. These data can be obtained free of charge via www.ccdc. cam.ac.uk/data_request/cif, or by emailing data_request@ccdc.cam.ac.uk, or by contacting The Cambridge Crystallographic Data Centre, 12 Union Road, Cambridge CB2 1EZ, UK; fax: +44 1223336033.

Author Contributions: Conceptualization: K.N.J., M.H., R.K. \& M.M.S.; Data curation: K.N.J., M.H. \& R.K.; Formal analysis: K.N.J.; Funding acquisition: K.N.J.; Investigation: K.N.J., M.H., R.K., W.B. \& S.E.K.; Methodology: 
K.N.J., M.H. \& M.M.S.; Project administration: K.N.J.; Software: D.S.; Supervision: K.N.J.; Validation: K.N.J.; Visualization: M.H. \& R.K.; Writing—original draft: K.N.J., M.H.; Writing—review \& editing: K.N.J. \& R.K.

Acknowledgments: K.N.J., D.S. and S.E.K. would like to acknowledge the SONATA grant (2014/15/D/ ST4/02856) of the National Science Centre in Poland for financial support. The research used resources of the Advanced Photon Source, a U.S. Department of Energy (DOE) Office of Science User Facility operated for the DOE Office of Science by Argonne National Laboratory under contract No. DE-AC02-06CH11357. Use of BioCARS was also supported by the National Institute of General Medical Sciences of the National Institutes of Health (NIH) under grant No. R24GM111072 (note: the content is solely the responsibility of the authors and does not necessarily represent the official views of NIH). Time-resolved set-up at Sector 14 was funded in part through collaboration with Philip Anfinrud (NIH/NIDDK). The authors thank the Wrocław Centre for Networking and Supercomputing (grant No. 285) for providing computational facilities. K.N.J. and R.K. thank Professor Philip Coppens (1930 - 2017) for scientific inspiration, and Yang Chen (Buffalo, USA) for early-stage syntheses.

Conflicts of Interest: The authors declare no competing financial interest.

\section{References}

1. Grätzel, M. Recent advances in sensitized mesoscopic solar cells. Acc. Chem. Res. 2009, 42, 1788-1798. [CrossRef]

2. Gimzewski, J.K.; Joachim, C. Nanoscale science of single molecules using local probes. Science 1999, 283, 1683-1688. [CrossRef] [PubMed]

3. Kamtekar, K.T.; Monkman, A.P.; Bryce, M.R. Recent advances in white organic light-emitting materials and devices (WOLEDs). Adv. Mater. 2010, 22, 572-582. [CrossRef] [PubMed]

4. Alibabaei, L.; Luo, H.; House, R.L.; Hoertz, P.G.; Lopez, R.; Meyer, T.J. Applications of metal oxide materials in dye sensitized photoelectrosynthesis cells for making solar fuels: Let the molecules do the work. J. Mater. Chem. A 2013, 1, 4133-4145. [CrossRef]

5. Arnold, N.; Bhatt, M.; Ried, T.; Wienberg, J.; Ward, D.C. Fluorescence in Situ Hybridization on Banded Chromosomes; Springer: New York, NY, USA, 1992.

6. Linfoot, C.L.; Leitl, M.J.; Richardson, P.; Rausch, A.F.; Chepelin, O.; White, F.J.; Yersin, H.; Robertson, N. Thermally activated delayed fluorescence (TADF) and enhancing photoluminescence quantum yields of $\left[\mathrm{Cu}^{\mathrm{I}} \text { (diimine)(diphosphine) }\right]^{+}$complexes-Photophysical, structural, and computational studies. Inorg. Chem. 2014, 53, 10854-10861. [CrossRef] [PubMed]

7. Ford, P.C.; Cariati, E.; Bourassa, J. Photoluminescence properties of multinuclear copper(I) compounds. Chem. Rev. 1999, 99, 3625-3647. [CrossRef] [PubMed]

8. Crosby, G.A. Structure, bonding, and excited states of coordination complexes. J. Chem. Educ. 1983, 60, 791-796. [CrossRef]

9. Kyle, K.R.; Ryu, C.K.; DiBenedetto, J.A.; Ford, P.C. Photophysical studies in solution of the tetranuclear copper(I) clusters $\mathrm{Cu}_{4} \mathrm{I}_{4} \mathrm{~L}_{4}$ (L = pyridine or substituted pyridine). J. Am. Chem. Soc. 1991, 113, 2954-2965. [CrossRef]

10. Radjaipour, M.; Oelkrug, D. Kinetik der Lumineszenz-Thermochromie und Zuordnung der Tieftemperaturemission von Pyridino-Kupfer(I)-jodid. Ber. Bunsen-Ges. Phys. Chem. 1978, 82, 159-163. [CrossRef]

11. Filatov, A.S.; Hietsoi, O.; Sevryugina, Y.; Gerasimchuk, N.N.; Petrukhina, M.A. Reversible $\mathrm{Cu}_{4} \leftrightarrow \mathrm{Cu}_{6}$ core interconversion and temperature induced single-crystal-to-single-crystal phase transition for copper(I) carboxylate. Inorg. Chem. 2010, 49, 1626-1633. [CrossRef]

12. Rigaku Oxford Diffraction. CRYSALIS PRO; Rigaku Oxford Diffraction: Yarnton, UK, 2018.

13. Bruker AXS. APEX3; Bruker AXS: Madison, WI, USA, 2015.

14. Oszlányi, G.; Sütő, A. Ab initio structure solution by charge flipping. Acta Cryst. Sect. A 2004, 60, $134-141$. [CrossRef] [PubMed]

15. Oszlányi, G.; Sütő, A. Ab initio structure solution by charge flipping. II. Use of weak reflections. Acta Cryst. Sect. A 2005, 61, 147-152. [CrossRef]

16. Palatinus, L. The charge-flipping algorithm in crystallography. Acta Cryst. Sect. B 2013, 69, 1-16. [CrossRef]

17. Palatinus, L.; Chapuis, G. Superflip-A computer program for the solution of crystal structures by charge flipping in arbitrary dimensions. J. Appl. Cryst. 2007, 40, 786-790. [CrossRef]

18. Petříček, V.; Dušek, M.; Palatinus, L. Crystallographic computing system JANA2006: General features. Z. Kristallogr. 2014, 229, 345-352. [CrossRef] 
19. Groom, C.R.; Bruno, I.J.; Lightfoot, M.P.; Ward, S.C. The Cambridge Structural Database. Acta Cryst. Sect. B 2016, 72, 171-179. [CrossRef] [PubMed]

20. Linderman, C.M.; Coppin, J.A.; O’Brien, C.; Cox, J.M.; Patel, D.D.G.; Benedict, J.B. The temperature dependent luminescent decay kinetics of an emissive copper complex in the single crystalline phase using time-gated luminescence microscopy. J. Lumin. 2016, 173, 30-33. [CrossRef]

21. Dunning, T.H. Gaussian basis sets for use in correlated molecular calculations. I. The atoms boron through neon and hydrogen. J. Chem. Phys. 1989, 90, 1007-1023. [CrossRef]

22. Peterson, K.A.; Puzzarini, C. Systematically convergent basis sets for transition metals. II. Pseudopotential-based correlation consistent basis sets for the group $11(\mathrm{Cu}, \mathrm{Ag}, \mathrm{Au})$ and $12(\mathrm{Zn}, \mathrm{Cd}, \mathrm{Hg})$ elements. Theor. Chem. Acc. 2005, 114, 283-296. [CrossRef]

23. Figgen, D.; Peterson, K.A.; Dolg, M.; Stoll, H. Energy-consistent pseudopotentials and correlation consistent basis sets for the $5 \mathrm{~d}$ elements Hf-Pt. J. Chem. Phys. 2009, 130, 164108. [CrossRef]

24. Yanai, T.; Tew, D.; Handy, N. A new hybrid exchange-correlation functional using the Coulomb-attenuating method (CAM-B3LYP). Chem. Phys. Lett. 2004, 393, 51-57. [CrossRef]

25. Chai, J.D.; Head-Gordon, M. Long-range corrected hybrid density functionals with damped atom-atom dispersion corrections. Phys. Chem. Chem. Phys. 2008, 10, 6615-6620. [CrossRef] [PubMed]

26. Grimme, S.; Antony, J.; Ehrlich, S.; Krieg, H. A consistent and accurate ab initio parameterization of density functional dispersion correction (DFT-D) for the 94 elements $\mathrm{H}-\mathrm{Pu}$. J. Chem. Phys. 2010, 132, 154104. [CrossRef] [PubMed]

27. Vreven, T.; Byun, K.S.; Komáromi, I.; Dapprich, S.; Montgomery, J.A.; Morokuma, K.; Frisch, M.J. Combining quantum mechanics methods with molecular mechanics methods in ONIOM. J. Chem. Theory Comput. 2006, 2, 815-826. [CrossRef]

28. Kamiński, R.; Schmøkel, M.S.; Coppens, P. Constrained excited-state structure in molecular crystals by means of the QM/MM approach: Toward the prediction of photocrystallographic results. J. Phys. Chem. Lett. 2010, 1, 2349-2353. [CrossRef]

29. Kamiński, R.; Jarzembska, K.N.; Domagała, S. CLUSTERGEN: A program for molecular cluster generation from crystallographic data. J. Appl. Cryst. 2013, 46, 540-543. [CrossRef]

30. Frisch, M.J.; Trucks, G.W.; Schlegel, H.B.; Scuseria, G.E.; Robb, M.A.; Cheeseman, J.R.; Scalmani, G.; Barone, V.; Petersson, G.A.; Nakatsuji, H.; et al. Gaussian 16 Rev. B.01; Gaussian Inc.: Wallingford, CT, USA, 2016.

31. Plasser, F.; Lischka, H. Analysis of excitonic and charge transfer interactions from quantum chemical calculations. J. Chem. Theory Comput. 2012, 8, 2777-2789.

32. Plasser, F.; Dreuw, A. High-level ab initio computations of the absorption spectra of organic iridium complexes. J. Phys. Chem. A 2015, 119, 1023-1036. [CrossRef]

33. Plasser, F. TheoDORE: A Package for Theoretical Density, Orbital Relaxation, and Exciton Analysis. Available online: http:/ / theodore-qc.sourceforge.net/ (accessed on 30 November 2018).

34. Graber, T.; Anderson, S.; Brewer, H.; Chen, Y.-S.; Cho, H.; Dashdorj, N.; Henning, R.W.; Kosheleva, I.; Macha, G.; Meron, M.; et al. BioCARS: A synchrotron resource for time-resolved X-ray science. J. Synchrotron Rad. 2011, 18, 658-670. [CrossRef]

35. Coppens, P.; Makal, A.; Fournier, B.; Jarzembska, K.N.; Kamiński, R.; Basuroy, K.; Trzop, E. A priori checking of the light-response and data quality before extended data collection in pump-probe photocrystallography experiments. Acta Cryst. Sect. B 2017, 73, 23-26.

36. Makal, A.; Trzop, E.; Sokolow, J.; Kalinowski, J.; Benedict, J.; Coppens, P. The development of Laue techniques for single-pulse diffraction of chemical complexes: Time-resolved Laue diffraction on a binuclear rhodium metal-organic complex. Acta Cryst. Sect. A 2011, 67, 319-326. [CrossRef]

37. Kamiński, R.; Graber, T.; Benedict, J.B.; Henning, R.; Chen, Y.-S.; Scheins, S.; Messerschmidt, M.; Coppens, P. Optimizing the accuracy and precision of the single-pulse Laue technique for synchrotron photo-crystallography. J. Synchrotron Rad. 2010, 17, 479-485. [CrossRef] [PubMed]

38. Coppens, P.; Fournier, B. New methods in time-resolved Laue pump-probe crystallography at synchrotron sources. J. Synchrotron Rad. 2015, 22, 280-287. [CrossRef] [PubMed]

39. Coppens, P.; Pitak, M.; Gembicky, M.; Messerschmidt, M.; Scheins, S.; Benedict, J.B.; Adachi, S.-I.; Sato, T.; Nozawa, S.; Ichiyanagi, K.; et al. The RATIO method for time-resolved Laue crystallography. J. Synchrotron Rad. 2009, 16, 226-230. [CrossRef] 
40. Szarejko, D.; Kamiński, R.; Jarzembska, K.N. Seed-skewness algorithm for X-ray diffraction signal detection in the time-resolved synchrotron Laue photocrystallography. J. Appl. Cryst. 2019, submitted.

41. Kalinowski, J.; Makal, A.; Coppens, P. The LaueUtil toolkit for Laue photocrystallography: I. Rapid orientation matrix determination for intermediate size unit-cell Laue data. J. Appl. Cryst. 2011, 44, 1182-1189. [CrossRef] [PubMed]

42. Kalinowski, J.; Fournier, B.; Makal, A.; Coppens, P. The LaueUtil toolkit for Laue photocrystallography: II. Spot finding and integration. J. Synchrotron Rad. 2012, 19, 637-646. [CrossRef] [PubMed]

43. Blessing, R.H. Data reduction and error analysis for accurate single crystal diffraction intensities. Cryst. Rev. 1987, 1, 3-58. [CrossRef]

44. Blessing, R.H. Outlier treatment in data merging. J. Appl. Cryst. 1997, 30, 421-426. [CrossRef]

45. Fournier, B.; Coppens, P. On the assessment of time-resolved diffraction results. Acta Cryst. Sect. A 2014, 70, 291-299. [CrossRef]

46. Fournier, B.; Sokolow, J.; Coppens, P. Analysis of multicrystal pump-probe data sets. II. Scaling of ratio data sets. Acta Cryst. Sect. A 2016, 72, 250-260. [CrossRef]

47. Coppens, P.; Fournier, B. On the scaling of multicrystal data sets collected at high-intensity X-ray and electron sources. Struct. Dyn. 2015, 2, 064101. [CrossRef]

48. Kamiński, R.; Jarzembska, K.N.; Kutyła, S.E.; Kamiński, M. A portable light-delivery device for in situ photocrystallographic experiments at home laboratory. J. Appl. Cryst. 2016, 49, 1383-1387. [CrossRef]

49. Tretiak, S.; Mukamel, S. Density matrix analysis and simulation of electronic excitations in conjugated and aggregated molecules. Chem. Rev. 2002, 102, 3171-3212. [CrossRef]

50. Coppens, P. Molecular excited-state structure by time-resolved pump-probe X-ray diffraction. What is new and what are the prospects for further progress? J. Phys. Chem. Lett. 2011, 2, 616-621. [CrossRef]

51. Vorontsov, I.; Pillet, S.; Kamiński, R.; Schmøkel, M.S.; Coppens, P. LASER-A program for response-ratio refinement of time-resolved diffraction data. J. Appl. Cryst. 2010, 43, 1129-1130. [CrossRef]

52. Vitale, M.; Ryu, C.K.; Palke, W.E.; Ford, P.C. Ab initio studies of the copper(I) tetramers $\mathrm{Cu}_{4} \mathrm{X}_{4} \mathrm{~L}_{4}(\mathrm{X}=\mathrm{I}, \mathrm{Br}$, $\mathrm{Cl})$. Effects of cluster structure and of halide on photophysical properties. Inorg. Chem. 1994, 33, 561-566. [CrossRef]

53. Knorr, M.; Khatyr, A.; Aleo, A.-D.; El Yaagoubi, A.; Strohmann, C.; Kubicki, M.M.; Rousselin, Y.; Aly, S.; Lapprand, A.; Fortin, D.; et al. Copper(I) halides (X = Br, I) coordinated to bis(arylthio)methane ligands: Aryl substitution and halide effects on the dimensionality, cluster size, and luminescence properties of the coordination polymers. Cryst. Growth Des. 2014, 14, 5373-5387. [CrossRef]

54. De Angelis, F.; Fantacci, S.; Sgamellotti, A.; Cariati, E.; Ugo, R.; Ford, P.C. Electronic transitions involved in the absorption spectrum and dual luminescence of tetranuclear cubane $\left[\mathrm{Cu}_{4} \mathrm{I}_{4}\right.$ (pyridine) $\left.{ }_{4}\right]$ cluster: A density functional theory/time-dependent density functional theory investigation. Inorg. Chem. 2006, 45, 10576-10584. [CrossRef] [PubMed]

55. Perruchas, S.; Tard, C.; Le Goff, X.F.; Fargues, A.; Garcia, A.; Khalal, S.; Saillard, J.Y.; Gacoin, T.; Boilot, J.P. Thermochromic luminescence of copper iodide clusters: The case of phosphine ligands. Inorg. Chem. 2011, 50, 10682-10692. [CrossRef]

(C) 2019 by the authors. Licensee MDPI, Basel, Switzerland. This article is an open access article distributed under the terms and conditions of the Creative Commons Attribution (CC BY) license (http://creativecommons.org/licenses/by/4.0/). 